\title{
Analysis of combustion acoustic phenomena in compression-ignition engines using large eddy simulation 라
}

\author{
Cite as: Phys. Fluids 32, 085101 (2020); doi: 10.1063/5.0011929 \\ Submitted: 27 April 2020 - Accepted: 9 July 2020 • \\ Published Online: 3 August 2020
}

\begin{abstract}
A. Broatch, ${ }^{7}$ (D) R. Novella, ${ }^{1}$ (D) J. García-Tíscar, ${ }^{1}$ (D) J. Gomez-Soriano, ${ }^{1, a)}$ (iD and P. Pal ${ }^{2}$ (iD
AFFILIATIONS

${ }^{1}$ CMT-Motores Térmicos, Universitat Politècnica de València, Camino de Vera, 46022 Valencia, Spain

${ }^{2}$ Energy Systems Division, Argonne National Laboratory, Lemont, Illinois 60439, USA
\end{abstract}

a) Author to whom correspondence should be addressed: jogosol@mot.upv.es

\begin{abstract}
As computational capabilities continue to grow, exploring the limits of computational fluid dynamics to capture complex and elusive phenomena, which are otherwise difficult to study by experimental techniques, is one of the main targets for the research community. This paper presents a detailed analysis of the physical processes that lead to combustion noise emissions in internal combustion engines. In particular, diesel combustion in a compression-ignition (CI) engine is studied in order to understand the singular behavior of the in-cylinder flow field responsible for the acoustic emissions. The main objective is, therefore, to improve the understanding of the phenomena involved in $\mathrm{CI}$ engine noise using large eddy simulations. Several visualization methods are employed to investigate the connection between combustion behavior and its effects on the pressure field. In addition, proper orthogonal decomposition is used to analyze the modal energy distribution among all the acoustic modes. The results show that the acoustic signature is fundamentally conditioned by the intensity of the premixed combustion rather than by the pressure oscillations generated by turbulent fluctuations in the flame surface established during the diffusion stage.
\end{abstract}

Published under license by AIP Publishing. https://doi.org/10.1063/5.0011929

\section{INTRODUCTION}

With millions of units in operation, the internal combustion engine (ICE) remains the most predominant propulsion system in the world. It is precisely its ubiquity that brings us to one of its most relevant issues: noise pollution. Links between traffic noise and increased sleep disorders, hypertension, strokes, and mortality have been established, especially in urban environments where engine noise is prevalent over tire noise due to lower speeds and people living, working, and sleeping close to busy roads.

Studies by the European Environment Agency have found that more than $70 \times 10^{6}$ people in European cities alone are subjected to day-evening-night noise levels $\left(L_{\mathrm{den}}\right)$ above $55 \mathrm{~dB}$, while only $7 \%$ of the proposed solutions to ameliorate this social problem have been addressed to the source itself: automotive powertrains. ${ }^{2}$ As pressure mounts from both environmental regulators and much quieter electric alternatives, engine manufacturers are increasingly aware of the noise emission problem and are, thus, prioritizing the reduction in Noise, Vibration, and Harshness (NVH) issues in their design targets. Often, NVH mitigation is attempted outside of the design loop, when the configuration is nearly frozen, instead of treating these problems as design optimization parameters along with performance, efficiency, emission, etc.

At the same time, engine manufacturers are becoming increasingly reliant on Computational Fluid Dynamics (CFD) in order to speed up the design cycle and reduce their costs, since numerical models are more cost-effective than experimental engine test cells. A major area of interest is, therefore, the integration of engine acoustic behavior prediction into the early stages of the design loop carried out through numerical simulation. ${ }^{3}$ This would allow manufacturers to consider the effect of their design choices on noise emissions early on, leading to streamlined development processes and better optimized engine configurations. ${ }^{4,5}$ Specifically, research efforts are focused on new combustion strategies, based on decreasing 
the burning temperatures, ${ }^{6,7}$ which benefits in terms of efficiency, and pollutant emissions are confronted with the high noise levels developed by combustion.

However, although research on numerical simulation of combustion has remarkably progressed since its inception, literature on methodologies for acoustic characterization of compressionignition (CI) ICEs is still scarce, ${ }^{10}$ as research efforts are mostly concerned with gas turbine combustors and, in the field of reciprocating engines, with spark-ignition (SI) concepts.

While as a first approach one could be tempted to use the same numerical modeling strategies as those commonly employed in these cases when considering compression-ignition engines, it is crucial to first realize that the CI combustion process leads to the prevalence of different acoustic phenomena than those commonly considered in SI engines and continuous combustion devices.

\section{BACKGROUND}

\section{A. Combustion noise}

The combustion of a volume element with a reactive mixture leads to a sudden release of energy. Only a minor part of this energy contributes to noise generation. In a given combustor device, the emitted sound power is $\sim 5-6$ orders of magnitude less than its thermal input. However, combustion noise has been established as a critical issue not only in industrial environments but also in powertrain sectors such as aeronautical or road transport vehicles. Although all these combustion systems are completely different and their flame features can be distinct, the fundamentals of the origin of combustion noise are common among them. ${ }^{11}$ From a physical point of view, combustion noise is a result of the interaction between turbulence and combustion, ${ }^{12}$ and depending on the application, the contribution of each phenomenon may be completely different. The fundamental understanding of noise is, therefore, essential to analyze the connection between combustion and the corresponding acoustics.

In positive displacement devices such as reciprocating internal combustion engines (ICEs), the interplay of thermal and acoustic phenomena is especially singular due to their cyclic, unsteady operation $^{13,14}$ and the fact that the process occurs in a closed fluid domain. In addition, the acoustic damping due to the engine structure and ambient attenuation is a relevant aspect to consider. Since the early 1980s, multiple studies have focused on establishing a relation between the combustion noise source and the end user, thereby estimating how source phenomena translate to the externally radiated noise, where NVH analysis has evidenced completely different propagation patterns of the acoustic energy. ${ }^{15,16}$

Since it has been demonstrated that the acoustic response of the engine is highly non-linear and it is mainly related to the operating condition, 17 the engine block design and the acoustic insulation, ${ }^{15,18}$ further studies assessed the radiation through the engine by different approaches. Many research works estimate the acoustic path between the source and free-field conditions by a transfer function. ${ }^{19-21}$ Other authors ${ }^{17,22}$ found correlations between typical engine output parameters and both objective and subjective effects on noise. On the other hand, some researchers dedicated efforts to identify which are the main sources within the engine structure. ${ }^{23,24}$ Moreover, while Mao et al. ${ }^{25}$ optimized the engine block design using a finite-element model to improve the acoustic signature of the engine, others such as Duvigneau et al. ${ }^{26}$ resorted to CFD and simplified acoustic models to achieve an improved design.

Combustion noise, based on the phenomena involved, can be split into direct and indirect components. ${ }^{27}$ Direct noise is related to stochastic processes of volumetric contraction and expansion in the reaction region. ${ }^{28}$ This is originated by random fluctuations of heat release rate (HRR) due to the chemical reactions within the flame surface. Indirect noise, or entropy noise, is linked to temperature non-uniformities that are convectively transported. ${ }^{29}$ Although a given combustion system can emit both direct and indirect noises, ${ }^{30}$ the latter is an exclusive feature of continuous-flux systems, ${ }^{31}$ for example, entropy spots accelerated downstream of the gas turbine combustion chambers.

Being the sole source of noise emission in ICEs, direct noise occurs in a bounded region, and it is modified from the flame by the transmission from the combustion chamber to the far-field through the engine structure. ${ }^{33}$ In nature, direct noise is broadband since its sources are incoherent throughout the flame surface under a given stable operating condition. Therefore, it is a random phenomenon of turbulent combustion that radiates across a broadband of frequencies.

The acoustic response can also be different owing to the interference between the originated pressure waves and chamber walls. ${ }^{34}$ When feedback is established between the pressure perturbations and the turbulent combustion, an instability in the flame surface appears. The volume fluctuations caused by the unsteady combustion are propagated as pressure waves, whose interaction and reflection at the chamber boundaries force the gas to oscillate in different patterns, ${ }^{35}$ causing even more unsteady combustion. If the relationship among pressure waves phase fits, self-excited oscillations grow and discrete tones at resonant frequencies associated with the acoustic features of the combustion chamber emerge. ${ }^{3}$

This phenomenon, which may be observed as the presence of high-frequency oscillations in the in-cylinder pressure or as the characteristic broad peak in the spectrum, also cited by Priede, ${ }^{37}$ is traditionally referred to as combustion chamber resonance, reverberation, or even knocking. ${ }^{87}$ This acoustic interaction is also of great importance for the design of combustion chambers since it can be accompanied by extremely high noise levels ${ }^{38}$ and stiff pressure oscillations that may cause structural damage of several engine components. $^{39}$

\section{B. Combustion chamber acoustics in compression-ignition engines}

Since the work of Draper in $1938,{ }^{40}$ knock effects in SI combustion engines were investigated in comparison with the ideal vibration modes of a cylinder. Priede ${ }^{37}$ also indicated that "the frequency of gas oscillations is determined by the geometric shape of the combustion chamber," a concept that would be linked to resonance modes in a follow-up paper, ${ }^{41}$ in which he mentions the simple side-toside mode, already detected by Draper, ${ }^{40}$ when sudden knocking events occur in SI engines. However, neither of them had the means to resolve the actual, three-dimensional (3D) gas oscillation modes caused by the combustion and chamber geometry.

Targeting open chambers and assuming several simplifications, Hickling et al. ${ }^{35}$ tried to improve upon purely theoretical formulae 
using the Finite Element Method (FEM). Still, his 16-element, quiescent gas FEM model lacked the capability to resolve actual flow or combustion, or even small-scale gas oscillations, and thus, only a slight variation from the theoretical modal coefficients was obtained.

Considering the particular case of CI engines, all axial (longitudinal) modes are out of the human hearing range (traditionally bounded by $20 \mathrm{~Hz}$ and $20 \mathrm{kHz}$ ) owing to the characteristic length of the combustion chambers used in automotive applications. Similarly, the radial modes (also known as transverse azimuthal modes) of third order or higher are out of the human hearing range. On the contrary, the radial modes of first or second orders correspond to characteristic frequencies within the highly sensitive human perception range, ${ }^{17}$ and only the first circumferential (or transverse radial) mode falls within the hearing range.

The potential of computational methods for analyzing ICE chamber resonance modes was first demonstrated by Torregrosa et al. ${ }^{17}$ and Broatch et al. ${ }^{42}$ However, although wave motion across the chamber was successfully resolved and compared with theoretical cylinder modes, no realistic initial flow field or combustion models were used, introducing, instead, small regions of high pressure simulating the ignition points. Furthermore, Torregrosa et al. ${ }^{17}$ showed through calculations based on acoustic modal theory ${ }^{43}$ how the acoustic excitation point-in this case the ignition location-has an impact on the high-frequency pressure response.

This effect was reproduced later by Broatch et al. ${ }^{42}$ using more detailed CFD simulations. They also suggested that the amplitude of pressure oscillations is linked to the intensity and relative location of the excitation, which in engine terminology is equivalent to the spatial pressure gradients achieved and to the relative position of the ignition zones in the chamber. Following these previous works, this paper focuses on leveraging the capabilities of numerical simulations to predict and analyze the acoustic sources generated by CI combustion. Specifically, diesel combustion was chosen in this investigation due to its clear propensity to generate loud noise levels and a particularly annoying noise quality.

In addition, proper orthogonal decomposition (POD) was utilized to isolate the most relevant flow structures and further understand which noise generation mechanisms contribute to the overall combustion acoustics to a larger extent. The rest of the paper is organized as follows: The methodology used in this work is presented in Sec. III including the details of numerical setup, model validation, and POD technique. Section IV discusses the main findings of this study. Finally, the main conclusions from this work are presented in Sec. V.

\section{METHODOLOGY}

A CFD model of a CI engine was developed to reproduce the characteristics of diesel combustion. Since an inherent objective of this work is to contribute to the fundamental understanding of combustion noise for automotive engine applications, the engine was conscientiously selected for dealing with current design tendencies of the automotive industry. Table I summarizes the main specifications of the engine considered. The model was widely validated in previous publications ${ }^{10,44}$ within the unsteady Reynolds-averaged Navier-Stokes (URANS) framework.
TABLE I. Main specifications and injection system characterization of the engine.

\begin{tabular}{lc}
\hline \hline Engine type & CI diesel engine \\
\hline Number of cylinders $(-)$ & 4 in line \\
Displacement $\left(\mathrm{cm}^{3}\right)$ & 1600 \\
Bore-Stroke $(\mathrm{mm})$ & $75.0-88.3$ \\
Connecting rod length $(\mathrm{mm})$ & 13.7 \\
Compression ratio $(-)$ & $18: 1$ \\
Number of valves $(-)$ & 2 intake and 2 exhaust \\
Injector nozzles & 6 \\
Nozzle hole diameter $(\mu \mathrm{m})$ & 124 \\
Included spray angle $(\mathrm{deg})$ & 150 \\
\hline \hline
\end{tabular}

After the model implementation and validation, a detailed analysis of the solution was carried out to relate the distinct combustion phases to their corresponding acoustic sources, thus allowing a better understanding of the critical noise generation mechanisms and the phenomenology involved. Then, a modal decomposition technique was applied in order to further verify the conclusions and to quantify the relative contributions of different combustion acoustic sources.

\section{A. Numerical model}

A numerical model of the engine was developed ${ }^{45}$ in order to assess the unsteady flow field. Specifically, large eddy simulations (LESs) ${ }^{46}$ were used to approach the turbulence problem by performing a low-pass spatiotemporal filtering of the Navier-Stokes equations. In contrast to the unsteady Reynolds-averaged NavierStokes (URANS) formulation, this keeps the fluctuation information (although only up to the size of the chosen filter), so more realistic unsteady phenomena can be adequately resolved. ${ }^{47,48}$

The LES subgrid scale tensor is modeled using the one-equation dynamic structure model. ${ }^{48}$

A second-order central differencing scheme was used for spatial discretization, and a first-order implicit scheme was employed for temporal discretization.

The Redlich-Kwong equation ${ }^{49}$ was selected as the equation of state for calculating the compressible flow properties. Pressurevelocity coupling was achieved by using a modified Pressure Implicit with Splitting of Operators (PISO) method. ${ }^{50}$

For combustion modeling, the finite-rate chemistry model ${ }^{51}$ was employed along with a multi-zone (MZ) approach, with bins of $5 \mathrm{~K}$ in temperature and 0.05 in equivalence ratio. ${ }^{52}$ This approach has been previously employed in numerical studies ${ }^{53,54,88-90}$ to simulate combustion in both SI and CI engines.

A reduced chemical kinetic mechanism for primary reference fuels (PRF) based on Brakora and Reitz ${ }^{55}$ was used in this work to account for fuel chemistry, and n-heptane was used as the diesel surrogate. The referred mechanism was originally developed for approximating the kinetics of several mixtures of diesel, biodiesel, and gasoline fuels, allowing us to perform a fair comparison between several blends of those fuels. For the present study, iso-octane reactions were deactivated so as to predict diesel ignition features, thereby resulting in 42 species and 168 reactions. 


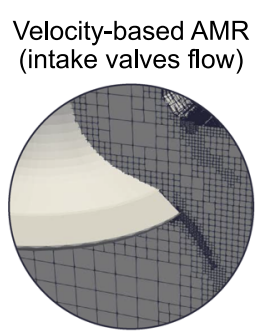

Spray and chamber embbeding

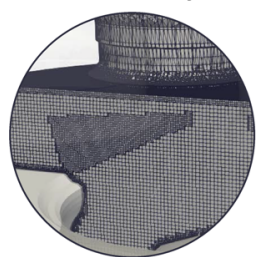

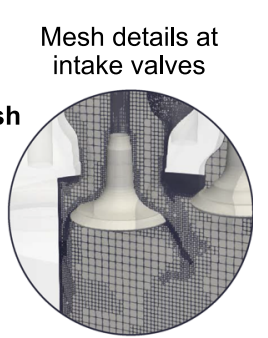

Temperature-based AMR (combustion process)

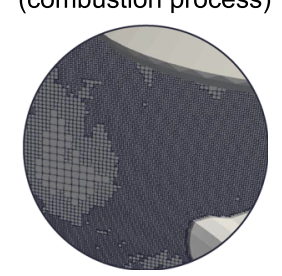

FIG. 1. Numerical domain and mesh characterization of the engine architecture.
The fuel injection was described by the standard Discrete Droplet Model (DDM). ${ }^{56}$ The injection droplet diameter distribution was assumed to be constant with a size of $124 \mu \mathrm{m}$, which coincides with the diameter of the injector nozzle. The Kelvin-Helmholtz (KH)-Rayleigh-Taylor (RT) breakup model was employed to model spray atomization. ${ }^{57}$ Droplet collision and coalescence were modeled by O'Rourke's model. ${ }^{58}$ Moreover, the Frossling correlation $^{59}$ was used to model fuel evaporation. The drag coefficient of the droplets was calculated by the dynamic drag model of Liu et al. ${ }^{60}$ Following the extensively accepted standard approach, ${ }^{61}$ diesel fuel physical properties were given by the diesel 2 fuel surrogate, ${ }^{62}$ which is known to provide suitable estimations of key spray parameters such as liquid length. ${ }^{62}$

The numerical domain, as shown in Fig. 1, included the complete single cylinder geometry and the intake/exhaust ports, allowing us to perform full cycle simulations.

The mesh discretization was performed using the cut-cell Cartesian method. The base mesh size was $2.2 \mathrm{~mm}$ throughout the domain in the reference grid configuration. Three levels of fixed embedding $(0.275 \mathrm{~mm}$ of cell size $)$ were added to the walls of the combustion chamber, ports, and the region near the fuel injector, to improve boundary layer prediction and the accuracy of spray atomization, droplet breakup/coalescence, etc. The mesh size in the

TABLE II. Wall temperatures used for the boundary conditions.

\begin{tabular}{lc}
\hline \hline Boundary condition & Temperature (K) \\
\hline Piston & 488.98 \\
Cylinder head & 484.14 \\
Liner & 398.25 \\
Valves (plate) & 484.14 \\
Valves (stem) & 351.45 \\
Intake ports & 351.45 \\
Exhaust ports & 401.36 \\
\hline \hline
\end{tabular}

chamber was reduced by two levels of embedding $(0.55 \mathrm{~mm}$ of cell size) after the start of combustion, for an improved recreation of the interaction and reflection of the pressure waves while avoiding undesired spatial aliasing effects. The CFD model also employed adaptive mesh refinement (AMR) to increase the grid resolution by four levels of refinement (up to $0.138 \mathrm{~mm}$ minimum cell size) based on the velocity and temperature subgrid scales of $1 \mathrm{~ms}^{-1}$ and $2.5 \mathrm{~K}$, respectively. As a result, the total number of cells varied between $13 \times 10^{6}$ and $25 \times 10^{6}$ during the simulation.

Wall temperatures were assumed to be constant and estimated using a lumped heat transfer model. ${ }^{63}$ These values are included in Table II for reference. The inflow/outflow boundaries placed at the end of the intake and exhaust ports were prescribed by the cycleaveraged values of the corresponding measured pressures and temperatures. Finally, all turbulence approaches were coupled with the wall heat transfer model developed by Angelberger et al. ${ }^{64}$

Several monitor points were distributed across the combustion chamber, including one at the same location as the pressure transducer in the experiments, in order to analyze the location of the standing waves. Moreover, the computed pressure was recorded at a sampling frequency of $50 \mathrm{kHz}$ so as to provide an aliasing-free bandwidth, sufficient to cover the human hearing range. ${ }^{65}$

\section{B. Numerical model validation}

On account of the particular behavior of the pressure field within the chamber, traditional in-cylinder pressure measurements through a single transducer do not provide enough information for characterizing all resonant phenomena completely. The oscillation patterns observed in the pressure cause distinct local pressure distributions that condition the signal registration. Hence, the simulated and measured signals must be recorded at the same location to ensure a fair comparison among them. The experimental pressure trace registered by a piezoelectric sensor is, therefore, compared to that obtained from a point monitor at the same location of the transducer in order to check the consistency of numerical results. If these signals match in temporal and frequency domains, the solution 
was considered to be suitable for extrapolation to the entire chamber domain.

The heat release due to combustion was also included for a qualitative validation of the combustion process. In the case of experiments, this parameter was obtained by solving the energy equation with the in-pressure measurement and assuming several simplifications. ${ }^{66}$ The equation is solved assuming uniform pressure and temperature fields through the whole combustion chamber, and it yields the instantaneous mean temperature and heat release. The latter parameter can be obtained considering additional hypotheses that allow us to separate heat loss to the walls and the apparent HRR. Furthermore, signal filtering is applied to the raw incylinder pressure to remove high-frequency oscillations. This procedure usually smoothens out some relevant information that subsequently conditions the HRR profile estimation itself. Due to all these simplifications, the parameters estimated by this method (such as ignition onsets and general trend) must only be considered as a reference.

The steady operating condition defined by an engine speed of $2400 \mathrm{rpm}$ and $168 \mathrm{Nm}$ of torque was selected to validate the numerical methodology. Full details of this operating condition are summarized in Table III. This configuration was specifically chosen to assure a high contribution of the resonance phenomena to the overall acoustics. In order to assure statically valid results from the simulation, several consecutive engine cycles were calculated. The first one, initialized from a well-validated URANS simulation, was removed to avoid possible convergence issues.

The validity of the results was judged using the uncertainty analysis proposed in Ref. 68 and later used by Probst et al. ${ }^{69}$ to estimate the minimum number of LES cycles that correctly capture the cycle-to-cycle variability (CCV) in a conventional spark-ignition engine. ${ }^{70}$ Similarly, we consider the uncertainty due to the number of engine cycles sampled in both the mean and the variation, quantified by the standard deviation (SD), as

$$
\begin{gathered}
\bar{x}+t_{\frac{\alpha}{2} ; v} \frac{s}{N} \leq \mu \leq \bar{x}+t_{\left(1-\frac{\alpha}{2}\right) ; v} \frac{s}{N}, \\
s \sqrt{\frac{N-1}{\chi_{\frac{\alpha}{2} ; v}^{2}}} \leq \sigma \leq s \sqrt{\frac{N-1}{\chi_{\left(1-\frac{\alpha}{2}\right) ; v}^{2}}},
\end{gathered}
$$

where the true mean $(\mu)$ and variation $(\sigma)$ were calculated from the sample mean $(\bar{x})$ and standard deviation $(s)$ for $N$ samples. The $t_{\frac{\alpha}{2} ; v}$ and $\chi_{\frac{\alpha}{2} ; v}^{2}$ values come from the t-distribution and chi-squared distribution for $1-\alpha$ and $v$ degrees of freedom, respectively.

\begin{tabular}{|c|c|c|c|}
\hline Engine speed (rpm) & \multicolumn{3}{|c|}{2400} \\
\hline Torque $(\mathrm{Nm})$ & \multicolumn{3}{|c|}{168.3} \\
\hline Number of injections (-) & \multicolumn{3}{|c|}{3 (2 pilots + main) } \\
\hline Injected mass $[\mathrm{mg} / \mathrm{str}]$ & 2.0 & 2.0 & 27.5 \\
\hline Injection timing (deg) & -36.3 & -14.1 & -0.1 \\
\hline Injection pressure $(\mathrm{MPa})$ & & 80 & \\
\hline Intake pressure $(\mathrm{MPa})$ & & 0.206 & \\
\hline
\end{tabular}

TABLE III. Details of the operating point considered in this work.
If the true means and variations overlap between the experiment and simulations, it is possible to claim that the model is capturing the same level of CCV observed in the experiments. Full details about this statistical method are widely explained in Ref. 68.

This procedure was applied after each cycle simulation until the aforementioned statistical demands were fulfilled, thereby giving the minimum number of required cycles. In this case, the three parameters plotted in Fig. 2 were considered: the maximum peak pressure, the noise intensity, and the pressure unsteady intensity. The noise intensity, also denoted as overall noise (ON) level, accounts for the noise levels emitted from the combustion chamber. ${ }^{9}$ Similarly, the pressure unsteady intensity accounts for the severity of high-frequency unsteady pressure oscillations. This parameter is also referred to in the literature as energy of resonance or reverberation. ${ }^{71}$ Results included in this figure correspond to the statistics achieved after each simulated cycle (8 in total, without considering the first simulated cycle).

Although it may seem a low number, results demonstrate that four realizations are sufficient to assure a statistically valid LES solution. Experiment and simulation mean/variation overlapped after the fourth engine cycle in all considered parameters.

After the statistical analysis, additional validation tasks were performed to check the suitability of the model to capture other relevant parameters and trends. In Fig. 3, the in-cylinder pressure measured data, including the experimental standard deviation data, are plotted against the numerical solution obtained from the model.

In general, the numerical model offers a good estimation of the in-cylinder pressure evolution since all simulated cycles are within experimental dispersion nearly throughout the cycle. Only a slight underestimation is observed in the numerical solution after the top dead center $\left(0^{\circ}\right)$, when the energy release of the mixing-controlled combustion phase reaches its maximum value. Nonetheless, it has been demonstrated that the method used to estimate the HRR from the experiments tends to underestimate the heat transfer toward the walls when local temperatures are well-above the average temperature of the combustion chamber surfaces, ${ }^{66}$ thereby over-predicting the HRR during these stages of the combustion process. This is particularly evident when the diffusive combustion is completely established and the sprays severely torch the piston surface.

Focusing on the zoomed-in views, it can be seen that the resonant oscillation is self-similar from cycle-to-cycle: the cyclic dispersion is very small, and the same oscillation peaks can be consistently identified. As expected, this cyclic variation is apparently reproduced although without reaching the dispersion levels $( \pm \mathrm{SD})$ seen in the measurements (the in-cylinder pressure at $20^{\circ}$ is $10.4 \pm 0.21 \mathrm{MPa}$ in the experiment and $10.1 \pm 0.18 \mathrm{MPa}$ in the simulation), since the model does not account for additional sources of dispersion such as mechanical deformations, variations in the injection mass and rate due to injector tolerances, inhomogeneities in the injected fuel and ingested air, asymmetries in heat transfer due to the coolant system, etc.

In addition to the in-cylinder pressure comparison, the heat release rate (HRR) is also included in Fig. 3. A reasonable agreement between experimental and simulated data is obtained. However, the simulation does not accurately predict the evolution of the HRR during the burning of both pilot injections, at least not at the same level of the main injection burning. Despite these differences between the 

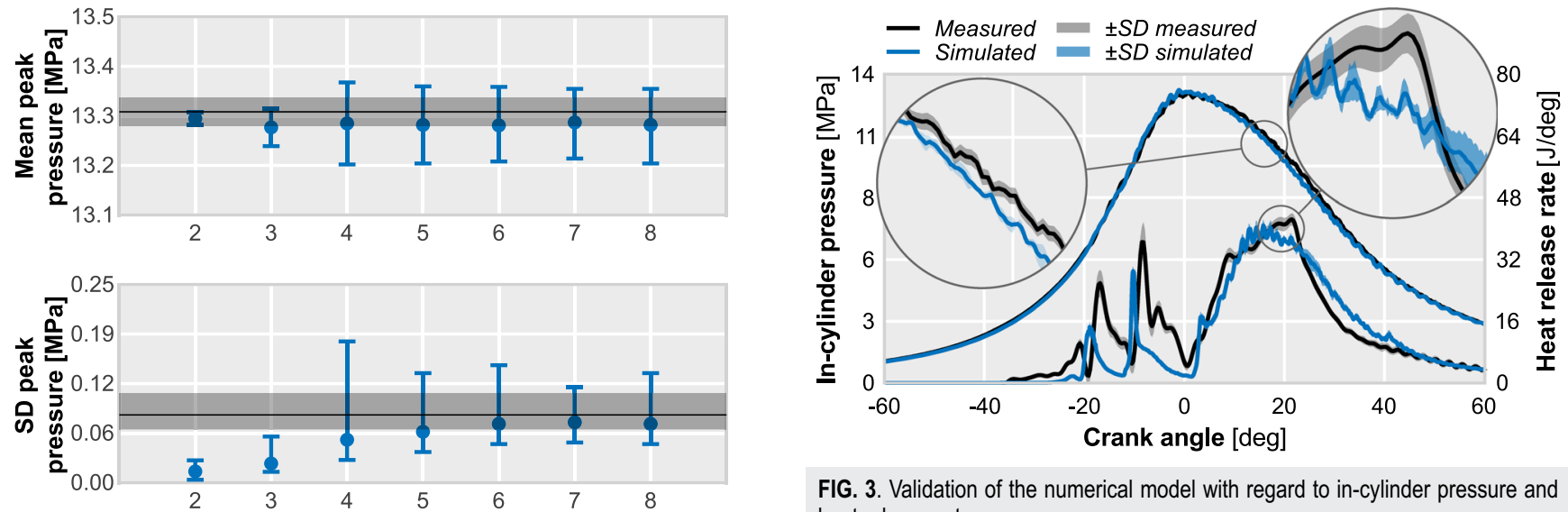

FIG. 3. Validation of the numerical model with regard to in-cylinder pressure and heat release rate.
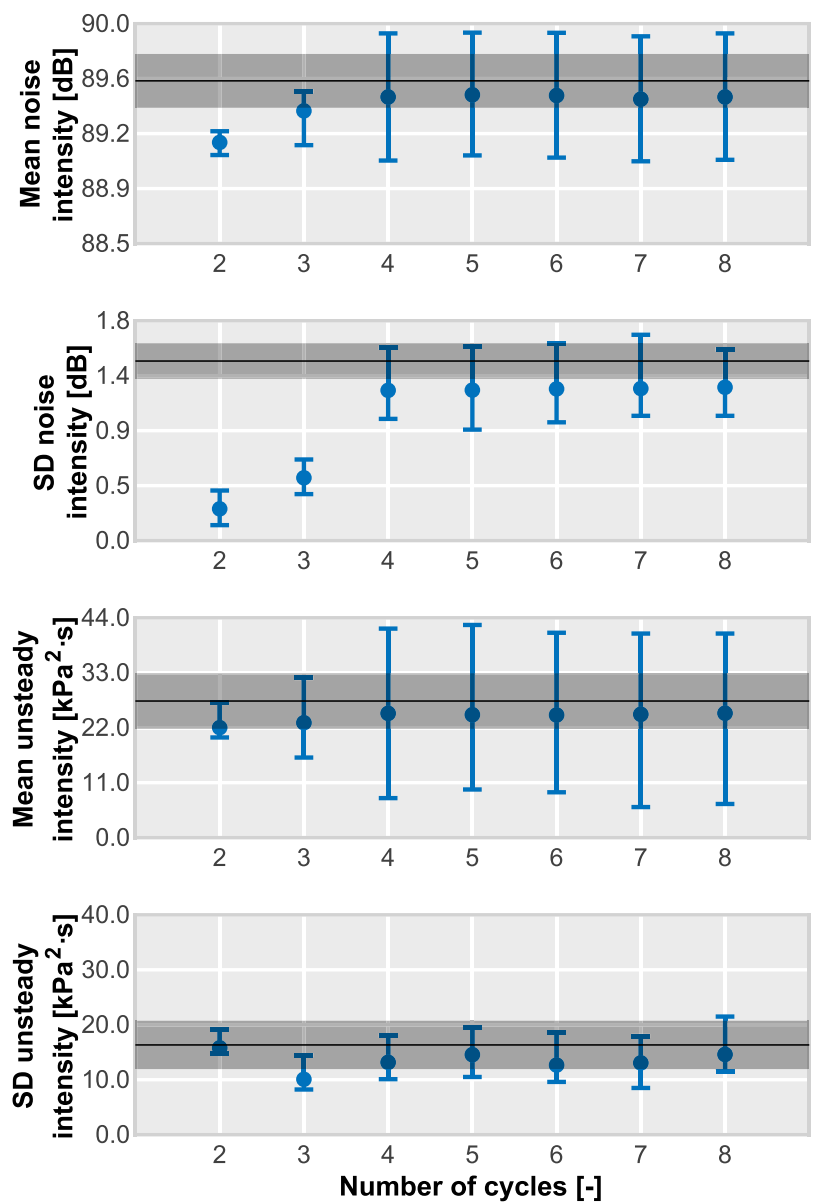

FIG. 2. Uncertainty study results. The maximum pressure peak, the pressure unsteady intensity, and the noise level were took into account.

curve estimated with the measured pressure and the curve predicted by the CFD simulation, trends are reasonably reproduced well and ignition delays are adequately captured. The time gap between the experiment and the simulation is $0.13 \mathrm{~ms}, 0.14 \mathrm{~ms}$, and $0.01 \mathrm{~ms}$ for

each ignition event (first pilot, second pilot, and main injection). The ignition times were calculated by the time step at which $10 \%$ of the fuel of each injection is burned. The disagreement observed during the low-temperature chemistry reactions, gathered between $-25^{\circ}$ and $-20^{\circ}$, is also remarkable. However, this is not especially critical due to its low impact on thermodynamic conditions. Cyclic dispersion levels drawn in this figure by the point-to-point SD are reproduced reasonably. These levels are more apparent during the combustion of the main injection where turbulence-spray interactions have a direct impact on the energy release, as shown in the right zoomed-in view of Fig. 3.

In Fig. 4, the sound pressure level is shown, indicating the source mechanism of each part of the spectral signature, following the method presented by Strahle, ${ }^{72}$ where the mechanical compression and mean combustion pressure trace are subtracted to identify the cutoff frequency (in this case, $\sim 4 \mathrm{kHz}$ ) above which the unsteady pressure oscillations are preponderant. It can be seen in the plot that all simulated data in this last part of the spectrum, which constitutes our range of maximum interest, are within the experimental standard deviation, suggesting that combustion-generated wave

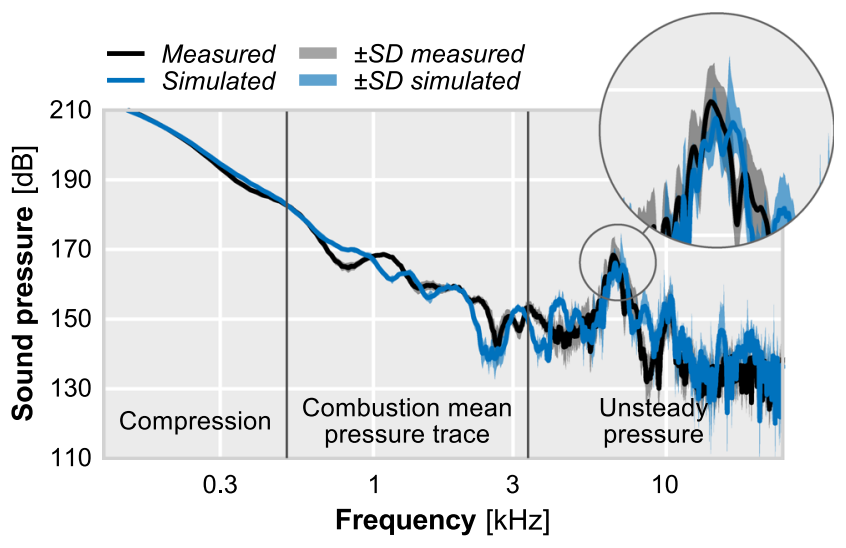

FIG. 4. Validation of the numerical model with regard to the sound pressure level. 
interaction is well captured by the numerical setup considered in this study. The pressure spectrum matches the experimental data, without any undue dissipation of the resonant peaks that could be induced by a badly posed numerical setup. The medium frequency range, gathered between $0.4 \mathrm{kHz}$ and $4 \mathrm{kHz}$, evidences a certain degree of disagreement. However, both the main trend and the average spectral content are similar, thus validating the numerical solution.

\section{Proper orthogonal decomposition}

Proper Orthogonal Decomposition (POD), also known as Principal Component analysis (PCA) and Karhunen-Loève expansion, was utilized to isolate the most relevant flow structures in order to further understand which noise generation mechanisms contribute to the overall combustion acoustics to a larger extent. POD can be performed gathering time snapshots of a system (in this case, of the pressure distribution in the chamber) as columns of a matrix $\mathbf{V}$ and then directly solving ${ }^{74}$ the eigensystem associated with the time-averaged spatial correlation matrix $\mathbf{V}^{\mathrm{T}} \mathbf{V}$ as

$$
\mathbf{V}=\mathbf{U} \boldsymbol{\Sigma} \mathbf{W}^{\mathrm{T}} \text {. }
$$

Here, $\mathbf{U}$ is a matrix whose columns $\boldsymbol{\Psi}_{i}$ contain the POD spatial modes that form the orthonormal basis of $\mathbf{V}$, which are also the eigenvectors of $\mathbf{V}^{\mathrm{T}} \mathbf{V}$. The diagonal matrix $\boldsymbol{\Sigma}$ contains the principal values $\sigma_{i}$ of $\mathbf{V}$, which correspond to the squared eigenvalues of $\mathbf{V}^{\mathrm{T}} \mathbf{V}$, thus solving the eigensystem of the time-averaged correlation matrix.

Using POD, numerous authors decomposed the flow field into its principal components, showing the contribution of each flow structure to the total flow field, ${ }^{75}$ thus addressing many combustion issues in internal combustion engines (ICEs). For instance, Chen et al. ${ }^{76}$ used POD to analyze misfires in spark-ignition engines, and cycle-to-cycle variation was widely studied by Bizon et al., ${ }^{77}$ and Dandby and Echekki ${ }^{78}$ tracked the evolution of different species along the engine cycle.

Nonetheless, it was not until Broatch et al. ${ }^{70}$ and Torregrosa et $a$ al. $^{67}$ when this technique was applied to the acoustic analysis of ICEs. Clear three-dimensional pressure modes were identified, reminiscent of classical open chamber acoustic modes ${ }^{35}$ but demonstrating for the first time the additional complex interaction of the pressure waves in different zones of the engine cylinder. Besides, they showed the energy share associated with each acoustic mode, thereby displaying a complete characterization of the acoustic energy distribution using POD.

\section{RESULTS AND DISCUSSION}

The numerical solution of the aforementioned LESs is used here in order to further analyze the origin of combustion unsteadiness and the subsequent acoustic behavior. Traditionally, CI engines operate with diesel-like fuels, characterized by a high cetane number to assure the auto-ignition of the air-fuel mixture. Due to the similarity observed among all simulated cycles, the following results correspond to the cycle number three, including those presented during the POD analysis (unless otherwise specified).

After the ignition, two different phases can be distinguished within the combustion process. ${ }^{79}$ Actually, there is a previous phase characterized by low-temperature chemistry reactions, ${ }^{80}$ although it will not be considered in this analysis due to its low relevance under the thermodynamic conditions. During the first phase, the charge is burned in a premixed mode at different locations inside the combustion chamber. The burning rate is primarily controlled by chemical kinetics, causing an abrupt energy release. In the second phase, a diffusion flame is established, and the energy may be assumed to be released at the same rate as the fuel mixes with air. The heat release rate is smoother than that in the previous phase, and local heat release rate fluctuations appear as a consequence of the interaction between turbulent transport and combustion.

Recalling the heat release rate (HRR) evolution shown in Fig. 3, it is possible to observe the combustion response at each burning stage. In this case, the process can be divided into three stages, one for each of the characteristic main "bumps" observed in the HRR trace that corresponds to a specific fuel injection event. In Fig. 5, the HRR evolution is drawn together with the maximum local temperature and the pressure oscillations registered at the transducer location in order to identify all characteristic combustion stages and timings. The Takeno flame index ${ }^{81}$ has been computed for each recorded snapshot to characterize the different combustion phases

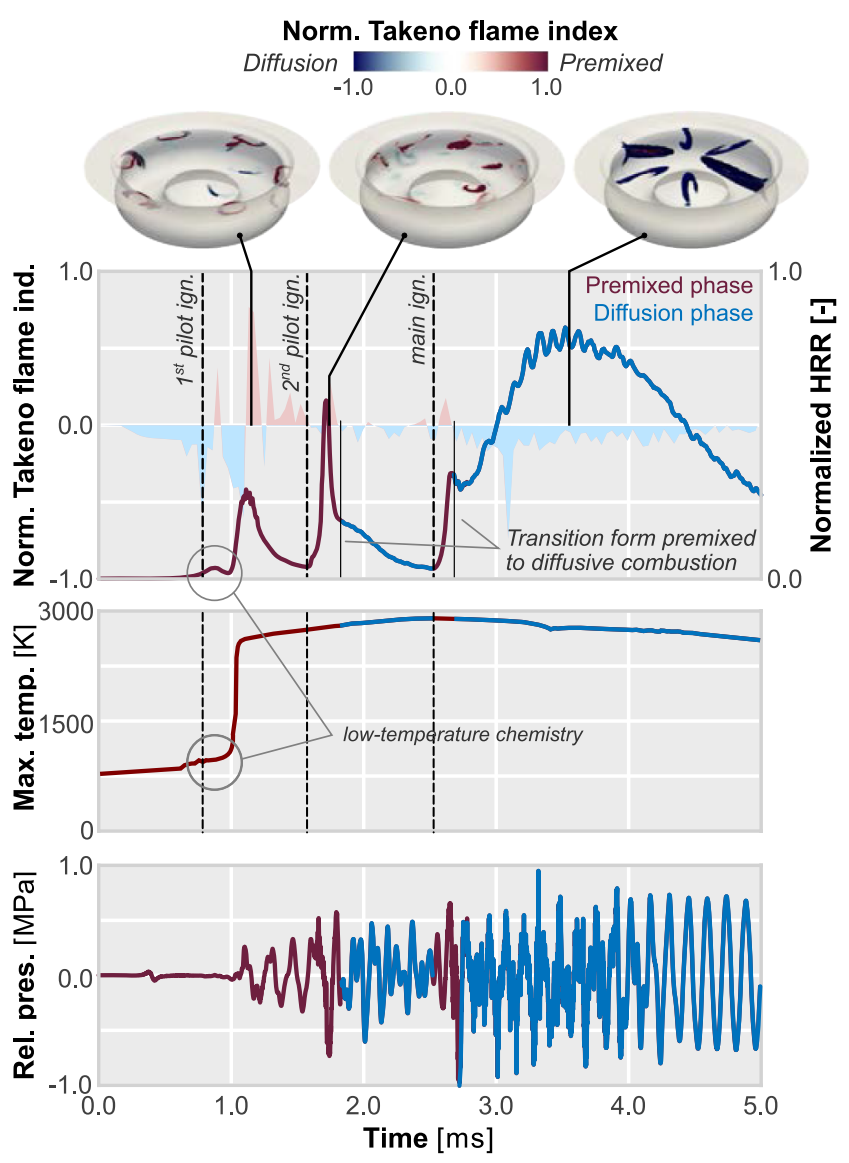

FIG. 5. Identification of the distinct combustion stages and phases. The energy release is plotted together with the pressure oscillation registered at the transducer location. 
precisely. In this way, the flame index at three instants representative of the different combustion regimes has been plotted in the same figure. Furthermore, the spatially averaged value of this index has been included for analyzing its temporal evolution.

As it can be seen, the fuel injected during the first pilot injection is practically burned under premixed conditions since the flame index is above zero almost throughout this stage. The maximum local temperature evolution reveals that only the first injection has a clear low-temperature chemistry region, but most of the combustion process develops under high-temperature heat release. The local flame index shows that combustion happens at the end of the spray plumes where the mixing conditions are close to the stoichiometric. The energy is rapidly released after the ignition, reaching a maximum $1.1 \mathrm{~ms}$ after the start of injection.

In the first instance, combustion during the second pilot injection is developed under premixed conditions as evidenced by global and local values of the flame index. However, the same index values show that the HHR drop observed after the local maximum is maintained by a short diffusive combustion.

Similarly, the main injection shows the same two-phase burning: the former is developed under premixed conditions and the latter, being significantly longer, takes place under diffusive conditions. During this last phase, the local flame index is clearly below zero and the heat release increases once the local maximum associated with the premixed phase is achieved.

Although the analysis of the pressure signal clearly shows how the unsteady oscillations arise just before the premixed combustion begins, there is no consensus on which combustion stage contributes to this phenomenon to a greater extent. Schuller et al., ${ }^{82}$ in collaboration with PSA Peugeot Citroën group, suggested that resonant oscillations are caused only by the stochastic fluctuations produced in the flame surface stabilized in the diffusion phase. On the contrary, the works of Torregrosa et al. ${ }^{17,42}$ suggest that pressure instabilities generated during the premixed combustion are significantly larger, and they dominate the acoustic source by far. Therefore, further analysis of the numerical data could help shed some light on this regard.

\section{A. Phenomenological analysis of combustion noise sources}

Once the fuel is injected inside the chamber, a region with high reactivity is formed at the end of the spray plume. The airfuel mixture within this region is rapidly consumed after spontaneous ignition, causing the aforementioned sudden energy release. Then, if the fuel is still being injected, a diffusive flame is established and the burning rate is now dominated by the turbulent transport. In both combustion stages, the energy release causes an increase in temperature that subsequently contributes to a rise in the mean pressure of the chamber, and the structure of the pressure field is changed. ${ }^{8}$

Figure 6 shows the evolution of the in-cylinder pressure field as combustion progresses. In this figure, the pressure field obtained by subtracting the spatially averaged pressure from the local pressure level is shown on a horizontal cut plane orthogonal to the cylinder axis and located $5 \mathrm{~mm}$ away from the cylinder head. The color scale was carefully fixed for a proper visualization of all pressure fluctuations. In addition, the threshold establishes the limit from

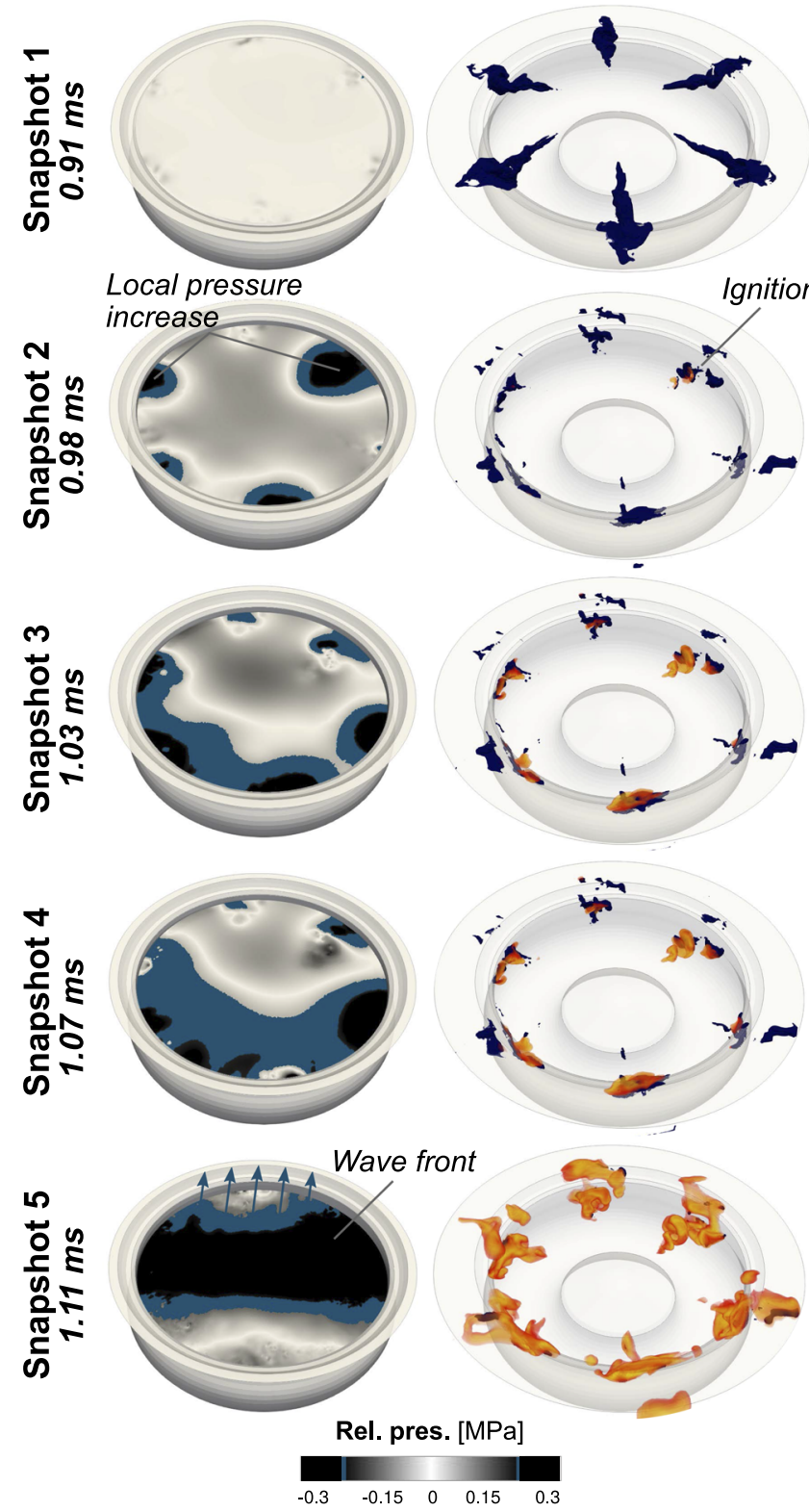

FIG. 6. Pressure field visualization along the first pilot combustion. The spatially averaged pressure evolution in the chamber is subtracted in order to clearly observe the unsteady pressure fluctuation. The spray-combustion interaction is showed via a combination of equivalence ratio and temperature clips.

which the pressure oscillation is below/above $0.2 \pm 0.01 \mathrm{MPa}$. This value represents $20 \%$ of the maximum oscillation magnitude registered within the chamber. The threshold helps us to track the wave front and to easily compare the magnitude of all pressure fluctuations observed in this and further studies. In addition, the spray is visualized by clipping the equivalence ratio $\phi$ at the unity, thereby showing the iso-volume of stoichiometric conditions enclosing the spray. In addition, the reaction surface is depicted as a clip of 
temperature higher than $2200 \mathrm{~K}$. This representation enables the observation of coupling effects between the injection and combustion while identifying the impact on the pressure field. The five snapshots show the most relevant phases of this combustion stage.

The spatial uniformity of the pressure field is evident in the first snapshot where the fuel is being injected for the first time inside the chamber. After few nanoseconds, several pressure waves spring at the end of the spray plumes caused by the ignition of the charge (snapshots 2 and 3). Finally, in the following instants (snapshots 4 and 5), the interaction between all originated pressure waves results in a macroscopic wave front traveling across the chamber.

Snapshots depicted in Fig. 7 show the instants after the first pilot ignition (without considering the low-temperature heat release). It can be seen from this sequence how this wave front travels from the top-right to the bottom-left side of the chamber. As soon as this wave reaches cylinder walls, it is reflected, producing a standing wave that modifies local pressure magnitudes following the already known oscillation patterns. ${ }^{35}$ It is important to note that this resulting wave collapses the color scale and surpasses the threshold previously defined, thus evincing that its amplitude is, at least, similar to the maximum oscillation magnitude observed during the process.

In the bottom timeline graph, the relative pressure registered at a specific point within the chamber is plotted. The distinct injection/combustion characteristic timings are included as well in order to identify possible links between the injection, combustion, and their acoustic responses. Ignition times $\left(\mathrm{B}_{\mathrm{i}}\right)$ were obtained by calculating the time step at which $10 \%$ of the fuel of each injection is consumed. As it can be seen, fuel from the first pilot injection burns completely under premixed conditions since ignition $\left(B_{1}\right)$ occurs well after the end of injection $\left(C_{1}\right)$, avoiding diffusion flame establishment. Thereby, the oscillation observed between $1.0 \mathrm{~ms}$ and $1.5 \mathrm{~ms}$ is purely caused by the motion of the pressure wave generated due to the premixed combustion of the first pilot injection.

The second pilot injection burning contributes to enhancing the generated standing wave. In Fig. 8, where the unsteady pressure field has been depicted following the same method as that in Fig. 7, it can be observed how the threshold is narrowed, suggesting an increase in the wave sharpness. Indeed, an amplitude increment in the pressure registered at the probe location is clearly evident in the aforementioned bottom graph.

Although there is a high-energy release due to premixed combustion during this stage (see Fig. 5), not all the combustion is developed under these conditions. As it can be seen in the bottom graph of Fig. 8, the ignition occurs before all fuel is injected into the chamber; note that ignition $\left(B_{2}\right)$ precedes the end of injection $\left(C_{2}\right)$ in the second pilot combustion phase.

In these images, the zoomed-in views of the spray jet are included again to relate combustion to the response of the unsteady pressure field. The first snapshot shows the instant at which the steady flame is being established. The transition between premixed and diffusion flames is determined by the Takeno index plotted in the bottom graph of Fig. 5. As it can be seen, this index switches from positive to negative values around $1.75 \mathrm{~ms}$ during the second pilot combustion. During this phase, the flame begins to cover the fuel jet as the reaction rate rises near stoichiometric regions. This phenomenon not only causes the aforementioned increase in the pressure wave amplitude but also generates a series of secondary pressure perturbations along the flame surface. Those perturbations can also be observed in the pressure trace in the form of smaller

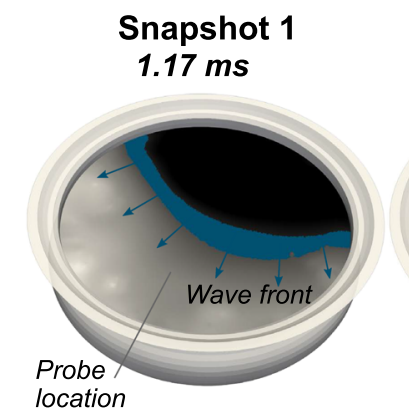

Snapshot 1
$1.17 \mathrm{~ms}$

location
Snapshot 2 $1.19 \mathrm{~ms}$

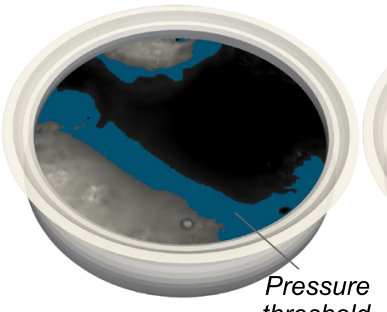

\section{Snapshot 3 $1.22 \mathrm{~ms}$}

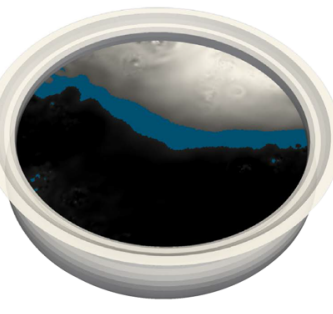

Snapshot 4 $1.24 \mathrm{~ms}$

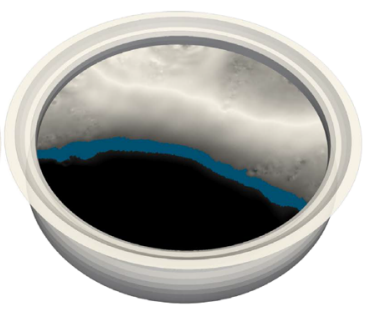

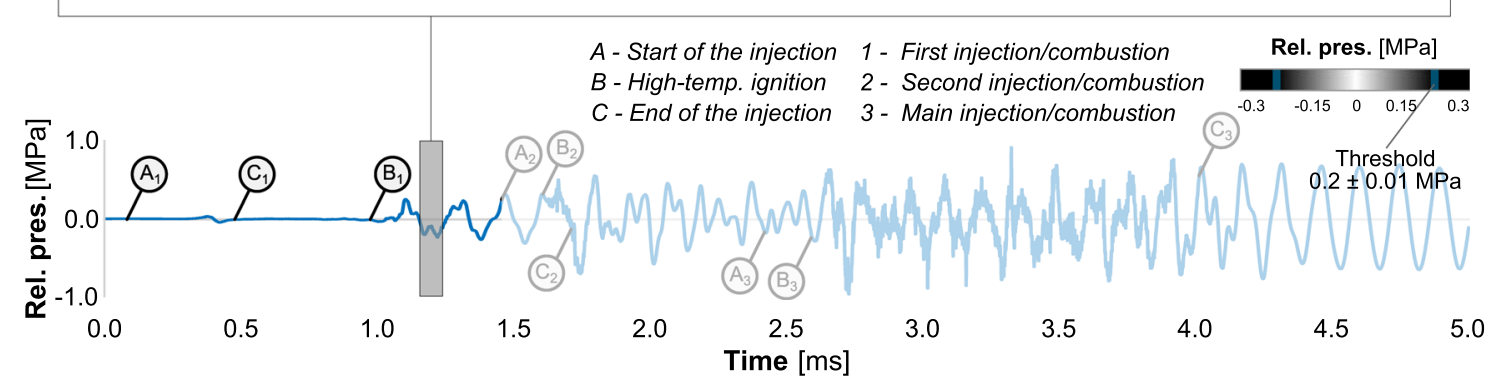

FIG. 7. Pressure field visualization after the first pilot combustion. The bottom graph shows the relative pressure signal registered at a point close to the transducer location. The highlighted $A$ and $C$ points correspond to the start and end of injection, while $B$ is the high-temperature ignition timing. Subscripts indicate the combustion stage; 1 is the first pilot phase, 2 is the second pilot phase, and 3 is the main injection phase. 


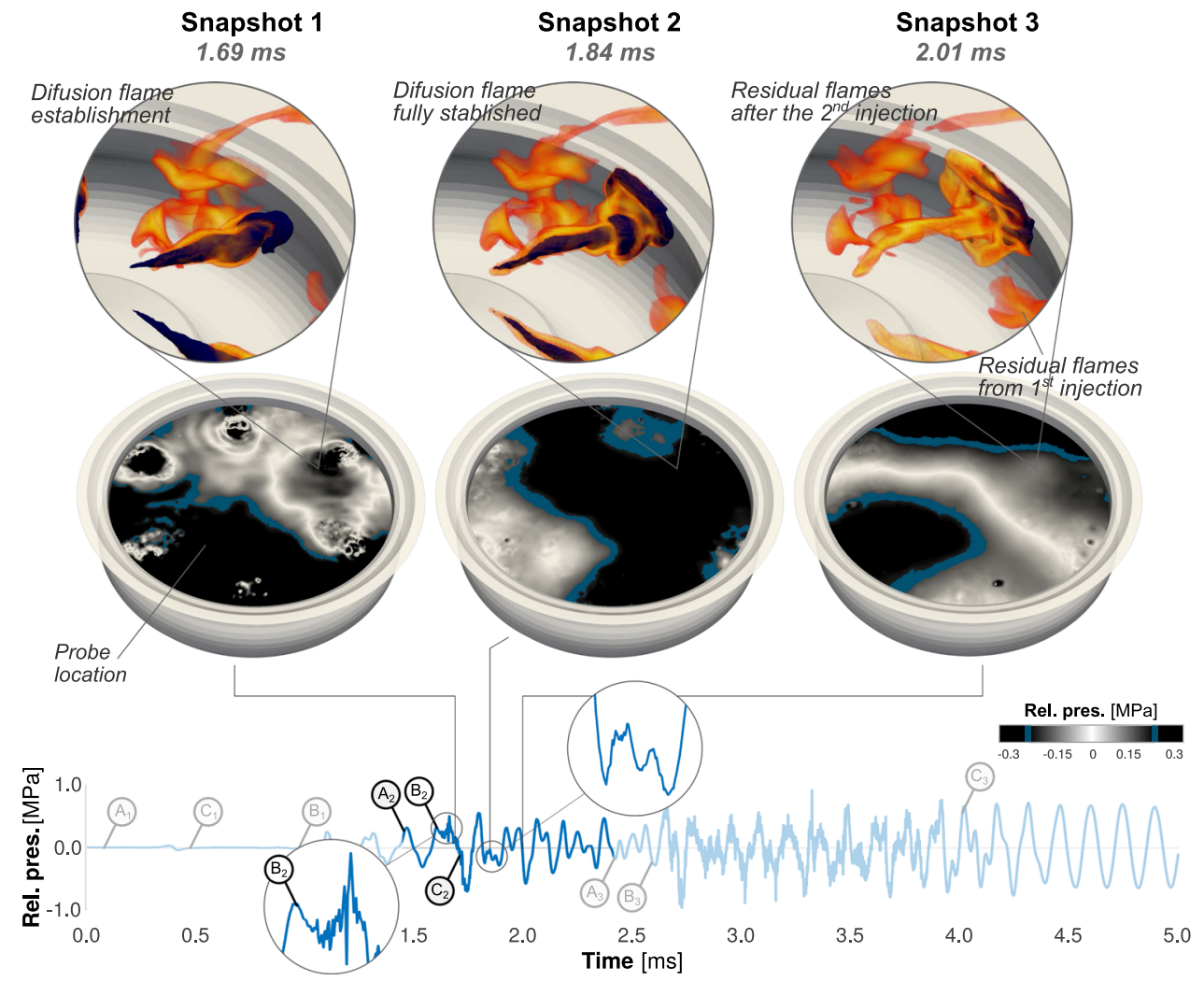

FIG. 8. Pressure field visualization during the second pilot combustion stage. Again, the spatially averaged pressure evolution in the chamber is subtracted in order to clearly observe the unsteady pressure fluctuations, whereas the spray-combustion interaction is showed by a combination of equivalence ratio and temperature clips. high-frequency oscillations, shown in the left zoomed-view of the pressure trace.

In the second snapshot, where the diffusion flame is completely established, the injection is already finished but the induced flow momentum allows us to keep the jet structure. The secondary oscillations, although still present, are notably reduced.

The final snapshot shows how the residual flames do not generate secondary perturbations as the jet momentum fades and only the standing wave generated during prior combustion stages remains dominant.

In order to extend the analysis done from the second pilot combustion stage to the main combustion one, a series of snapshots were chosen and are included in Fig. 9. This allows us to observe some elusive phenomena difficult to show in short diffusive burnings. Snapshots were specifically selected considering the distinct phases of combustion to allow a better comprehension of the interaction between pressure waves and the combustion process itself.

The first snapshot is focused on the transition between the premixed and diffusion combustion stages. In this case, the transition is around $2.74 \mathrm{~ms}$ (see Fig. 5). It can be observed that the diffusion flame settles along the spray plume as the injection progresses while multiple local pressure fluctuations arise.

Inspection of the pressure field indicates a particular spray ignition sequence. Sprays located at the exhaust side ignite earlier than those located at the intake side, contributing not only to the unsteadiness of the in-cylinder pressure field but also to generation of multiple asymmetries. This is due to a combined effect of the boundary conditions (exhaust ports are at higher temperature than the intake ones) and the path followed by the flow during the gas exchange process. ${ }^{84}$ In addition, an abrupt pressure rise is observed at the end of the spray plume as a consequence of the high burning rates experienced during premixed combustion.

Meanwhile, the heat release from the stabilized flame results in a fluctuating density that generates additional pressure waves. The turbulence-spray interaction between the chamber atmosphere and jets acts as a supplementary source of pressure perturbations, which contribute to the combustion acoustics. In Fig. 10, the interaction among the spray, combustion, and pressure field is shown for the same snapshots of Fig. 9. The pressure field is depicted around the spray plumes to easily identify coupling effects. Snapshots $2-5$ depict the same pressure structures already seen in the second pilot combustion stage but, in this case, during the main injection burning. These structures persist during the whole injection event from the initial spray structure (snapshot 1 ) to the fully established diffusion flame, also including when the sprays interact with the piston surface (snapshots 3 and 4 ).

Nevertheless, the standing wave generated during previous stages clearly remains as the largest pressure perturbation inside the chamber since the maximum amplitude of these secondary oscillations is clearly below $20 \%$ of the maximum overall amplitude. In addition, while the standing wave persists during the whole combustion process, diffusion-induced oscillations are rapidly 


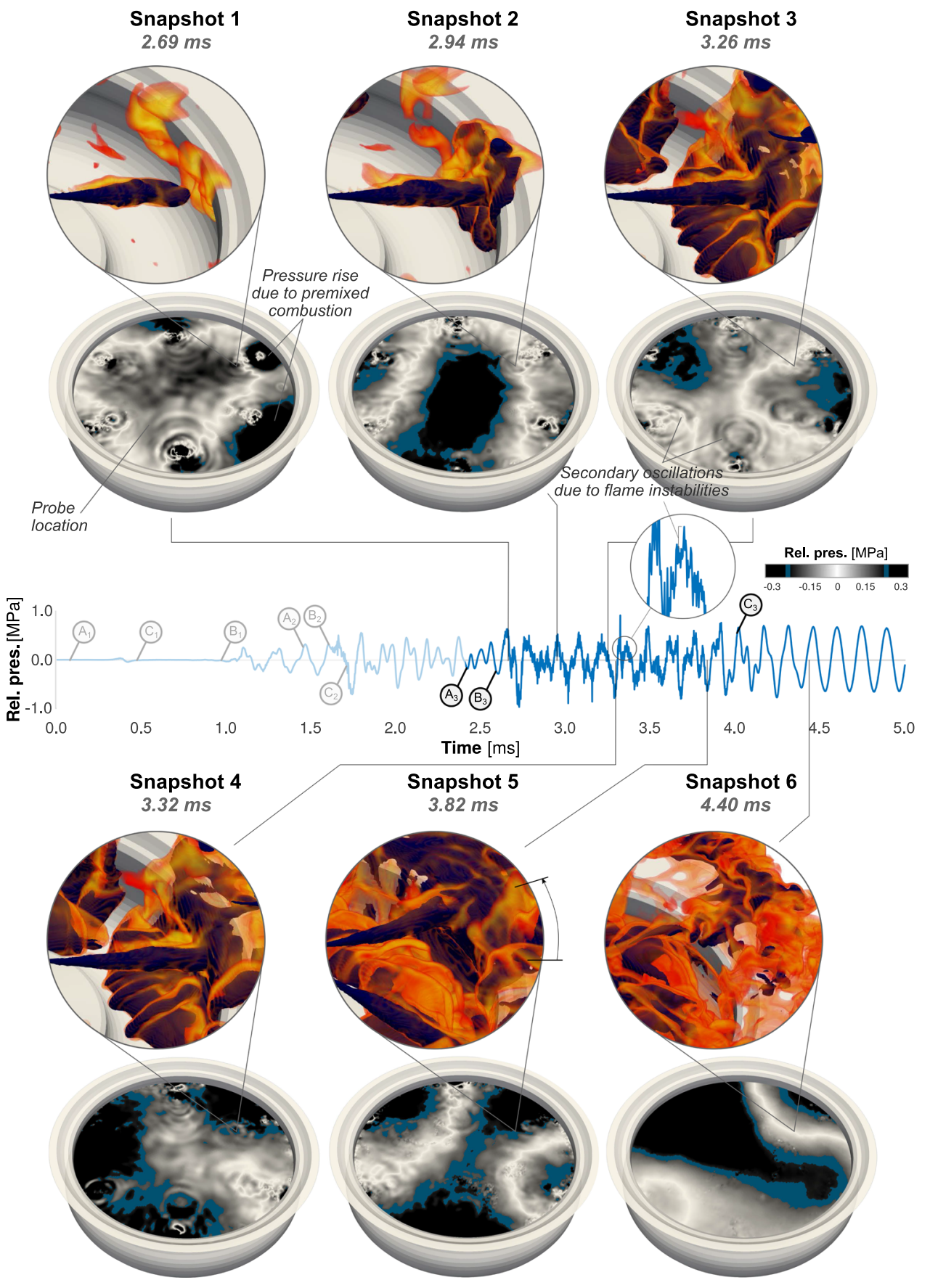

FIG. 9. Pressure field visualization during the main combustion stage, following the same visualization approach as in the previous figures.

attenuated when the fuel injection is finished (snapshot 6). As it can be seen in snapshot 5 , when the injection is almost finished and the spray plume is deformed by the swirl flow motion and the momentum loss, these secondary waves do not show such a clear structure, and as the timeline graph displays, their amplitudes are significantly smaller.
As shown, this phenomenological analysis allows a characterization of the pressure oscillations produced during the different combustion phases. Indeed, it reveals that pressure perturbations induced by the diffusion flame are negligible not only in comparison with the uniform pressure rise but also with the resonant standing waves. 


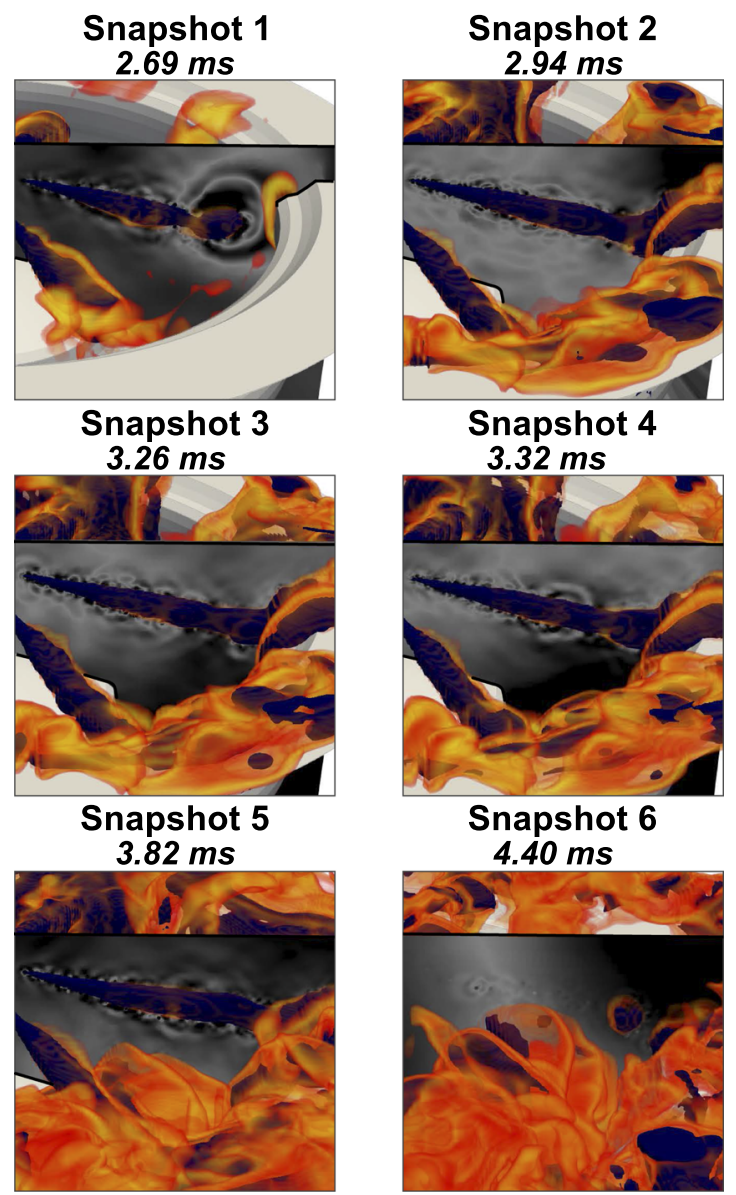

FIG. 10. Details of the interaction between spray, combustion, and pressure field. $A$ radial cut of the pressure field is depicted together with the spray visualization used previously.

\section{B. POD analysis}

Although the previous analysis allowed a clear view of which combustion mechanisms lead to acoustic emissions, the contribution of each of them to the overall acoustics has not been properly quantified. Therefore, it remains to be seen if pressure oscillations caused by the diffusion flame dynamics increase noise levels within the chamber in a significant way.

In this section, the proper orthogonal decomposition method was applied to the CFD solution in order to shed some light on this aspect. The method described by Torregrosa et al. ${ }^{67}$ was used for preparing the data for the POD calculation. Data from a given cycle were recorded at a constant time step using a frequency sample of $48 \mathrm{kHz}$ while keeping all relevant acoustic information. Then, the pressure field resulted after each converged time step was interpolated to a regular mesh. The study was made for each of the computed cycles, giving very similar results. Thus, for convenience, the analysis presented in this section corresponds to the third engine cycle.

Figure 11 shows an overview of the results obtained after the application of Torregrosa's POD methodology. ${ }^{67}$ In this figure, the energy distribution is plotted together with the spatial distribution of selected acoustic modes so as to identify which flow structures contribute to the overall emissions to a greater extent. As in the referred work, ${ }^{67}$ the first POD mode $\left(\boldsymbol{\Psi}_{1}\right)$ related to the mean homogeneous pressure is discarded to focus on the analysis of the unsteady behavior of combustion, rather than that of the compression-expansion cycle.

As Torregrosa's work ${ }^{67}$ shows, POD modes $\boldsymbol{\Psi}_{2-9}$ gather $~ 50 \%$ of the remaining acoustic energy. The spatial distribution of these high-energy modes is comparable to that reported by Hickling et al. ${ }^{35}$ For instance, Fig. 11 includes the structure of modes $\Psi_{2}$ and $\Psi_{7}$, being very similar to the asymmetric modes $(m=1, n=0)$ and ( $m=2, n=0)$ as denoted by Hickling.

Although not shown in this graph, modes $\Psi_{2-57}$ also exhibit scales similar to both cylinder and/or bowl diameters, already being similar to the structures reported by Hickling et al.

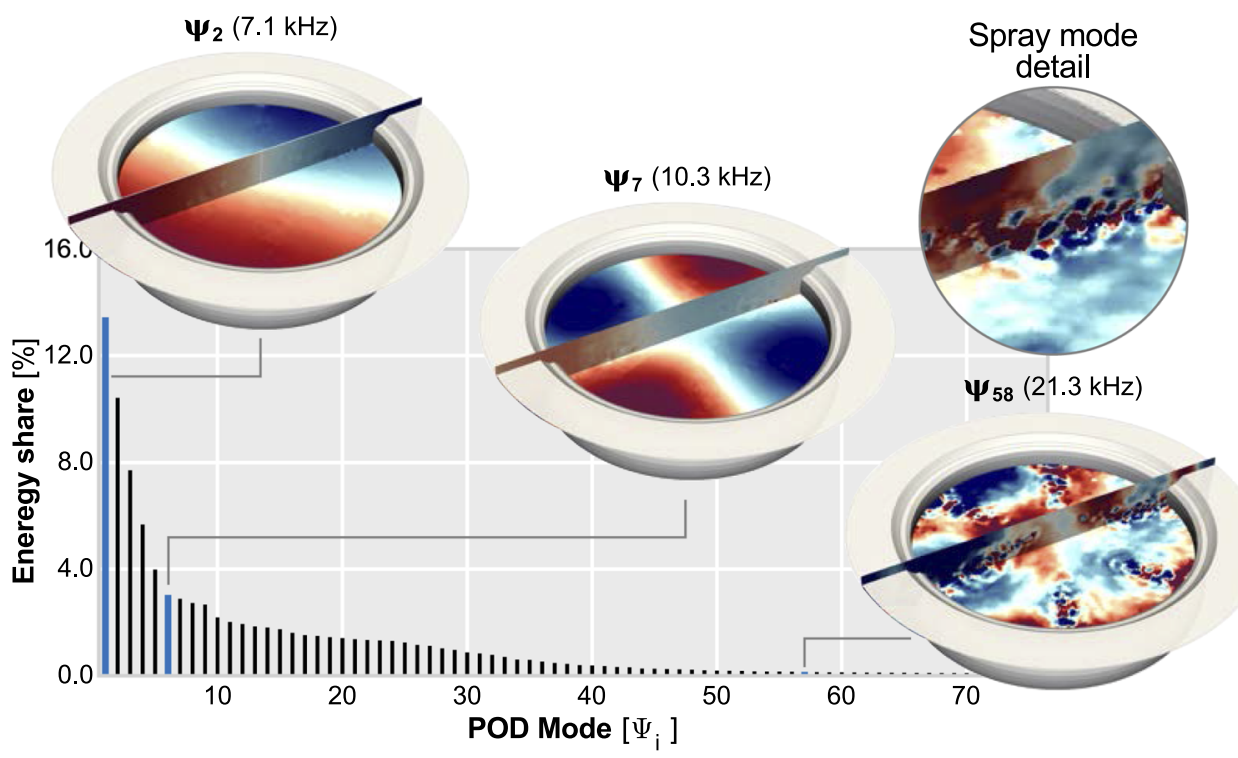

FIG. 11. Energy share distribution of POD modes, highlighting some of the most relevant chamber and spray related modes. Only $95 \%$ of the total acoustic energy is represented, disregarding the least relevant modes. 


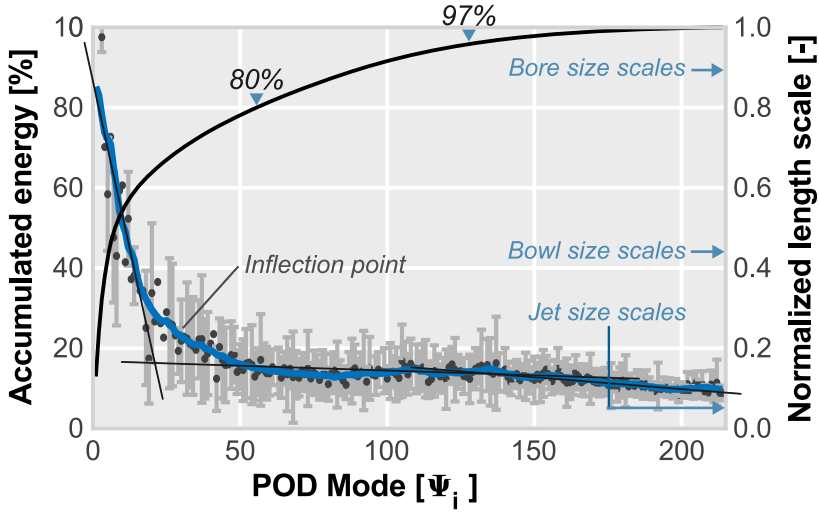

FIG. 12. Length scales of the most representative oscillation patterns. The accumulated energy is also included to relate the energy of each mode to its correspondent length scale.

Inspection of POD mode $\Psi_{58}$ shows a similar oscillation pattern to that reported in multiple works related to jet-induced combustion devices. ${ }^{85}$ These structures are characterized by opposed amplitude regions along the jet axis as a result of a helical $3 \mathrm{D}$ oscillation pattern. ${ }^{86}$ In all these works, similar flow structures were identified in multiple applications in which the fluctuating density in the stabilized flame was the main cause of noise emission.

Figure 12 relates the energy to the length scale of each POD mode. In this plot, the size of the oscillation patterns was estimated by computing the Euclidean distance between the maximum and the minimum mode magnitudes. As expected from previous figures, large scales accumulate most of the acoustic energy. In particular, modes $\Psi_{2-58}$, with a length scale comparable to both the bore and/or the bowl of the cylinder, gather more than $80 \%$ of the acoustic energy, thereby being the main contributors to engine acoustics.

In Fig. 13, more POD modes are drawn in order to illustrate this. As shown, POD modes $\boldsymbol{\Psi}_{2-10}$ have clear similarities to the theoretical modes reported by Hickling. The spatial structure becomes less defined as the relevance of the mode decreases, but always keeps large-scale patterns $\left(\Psi_{29-31}\right)$. Finally, the structures become more focused on small scales specifically related to spray plumes $\left(\Psi_{58-59}\right)$.

In addition, the inflexion point observed in the curve represents the transition between these large oscillation scales and those smaller oscillations related to the sprays burning. In this case, pressure oscillations induced by diffusion flame dynamics gather less than $20 \%$ of the total energy.

In order to confirm that the larger oscillation scales are originated during the premixed combustion, the amplitudes of three relevant POD modes $\left(\boldsymbol{\Psi}_{2,7,58}\right)$ are plotted in Fig. 14 for each time of the CFD simulation. These modes have been normalized by their respective maximum amplitudes in order to easily observe the inception point.

Inspecting the time evolution of these POD modes, clear relationships can be found between the inception of the modes and the

onset of the combustion of the different injections (denoted as in previous figures by $\mathrm{B}_{1-3}$ ). It can be seen how the onset of modes $\Psi_{2,7}$ is coincident with the time of $B_{1}$. On the other hand, mode $\Psi_{58}$ shows little relevance after $B_{1}$, only exhibiting a sudden rise in the amplitude after $B_{2}$, close to the transition between premixed and diffusion regimes $(1.75 \mathrm{~ms})$. This fact confirms that the larger scales are generated during the premixed combustion regime and the preponderance of the two pilot injections in creating the resonant field. Besides, small-scale oscillations are an intrinsic feature of diffusive combustion.
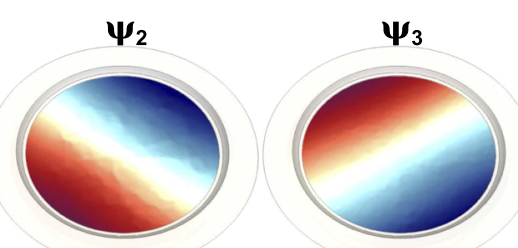

$\Psi_{5}$

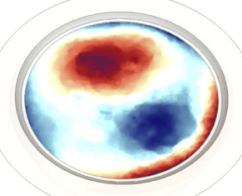

$\Psi_{8}$

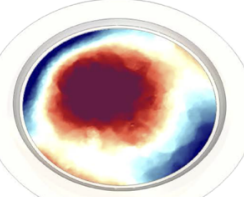

$\Psi_{29}$

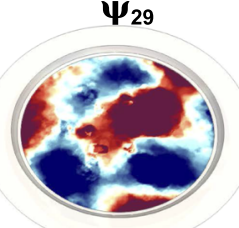

$\Psi_{57}$

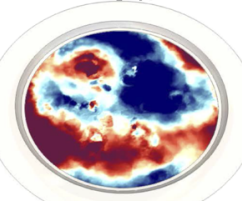

$\Psi_{200}$

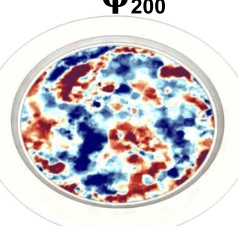

FIG. 13. Spatial distribution of POD modes across the simulated chamber. Each mode is represented by a contour slice of the real values of each individual mode $\mathfrak{R}\left\{\Psi_{i}\right\}$. 


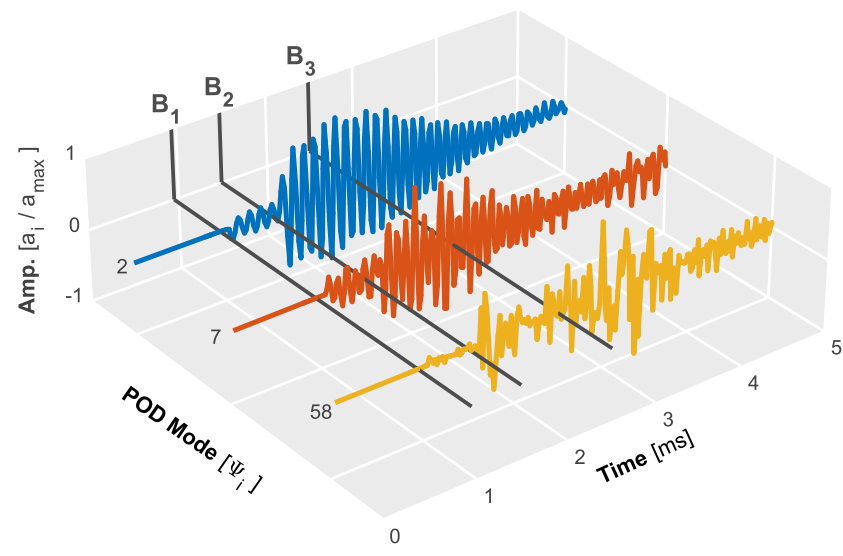

FIG. 14. Normalized amplitude of POD modes $\Psi_{2,7.58}$ in the time domain. Ten percent fuel burning times $B_{1-3}$ for each of the three combustions are included for reference.

\section{CONCLUSIONS}

In this paper, a complete characterization of combustion noise sources in a CI diesel engine has been performed, with regard to the analysis of phenomena involved in the noise generation and comprehension of the unsteady behavior caused by combustion.

A numerical model was employed in order to overcome experimental limitations while addressing the study of noise sources in detail, thereby providing valuable insights into all involved phenomena.

Two different sources of acoustic perturbations caused by the combustion were identified. The first, originated during the premixed combustion phase, produces a sudden increase in pressure at the end of the fuel spray plumes, which generates a resonant wave inside the chamber. The second one is originated from local density fluctuations around the diffusion flame and, however, is not a fully localized source since it spontaneously appears along the stabilized flame during the mixing-controlled combustion phase.

Inspection of the numerically obtained pressure field offers a qualitative way of characterizing the contribution of each source to the chamber acoustic signature. It is shown that these diffusioninduced oscillations are small and rapidly attenuated, when compared to the standing wave generated due to the premixed burning.

In addition to this qualitative characterization, a more in-depth study was carried out to verify this deduction. An analysis based on proper orthogonal decomposition was made to isolate coherent time-spatial flow features from the simulation.

Results revealed that modes characterized by large-scale structures (similar to the cylinder/bowl diameter) accumulate most of the acoustic energy inside the combustion chamber and also that the energy gathered by jet-related scales is insignificant. In this way, POD confirms outcomes offered by the inspection of the CFD solution.

\section{ACKNOWLEDGMENTS}

The equipment used in this work was partially supported by the FEDER project funds "Dotación de infraestructuras científico técnicas para el Centro Integral de Mejora Energética y Medioambiental de Sistemas de Transporte (CiMeT)" (Grant No. FEDERICTS-2012-06), framed in the operational program of unique scientific and technical infrastructure of the Spanish government.

J. Gomez-Soriano was partially supported through the Programa de Apoyo para la Investigación y Desarrollo (PAID) of Universitat Politècnica de València (Grant No. FPI-S2-2016-1353).

The submitted manuscript was created partly by UChicago Argonne, LLC, Operator of Argonne National Laboratory. Argonne, a U.S. Department of Energy Office of Science laboratory, is operated under Contract No. DE-AC02-06CH11357. This research was partly funded by the U.S. DOE Office of Vehicle Technologies, Office of Energy Efficiency and Renewable Energy, under Contract No. DEAC02-06CH11357. The authors wish to thank Gurpreet Singh and Michael Weismiller, program managers at the DOE, for their support. In addition, the authors would like to acknowledge the Laboratory Computing Resource Center (LCRC) at the Argonne National Laboratory for computing time on the Bebop cluster that was used in this research.

The authors want to express their gratitude to CONVERGENT SCIENCE, Inc. and Convergent Science GmbH for their kind support for the CFD calculations with the CONVERGE software.

\section{DATA AVAILABILITY}

The data that support the findings of this study are available from the corresponding author upon reasonable request.

\section{REFERENCES}

${ }^{1}$ A. L. Brown, "Effects of road traffic noise on health: From burden of disease to effectiveness of interventions," Procedia Environ. Sci. 30, 3-9 (2015).

${ }^{2}$ C. Nugent, N. Blanes, J. Fons, M. Sáinz de la Maza, M. J. Ramos, F. Domingues, A. van Baek, and D. Houthuijs, "Noise in Europe 2014," Technical Report 62, European Environment Agency, 2014.

${ }^{3}$ H. Huang, Z. Zhu, Y. Chen, Y. Chen, D. Lv, J. Zhu, and T. Ouyang, "Experimental and numerical study of multiple injection effects on combustion and emission characteristics of natural gas-diesel dual-fuel engine," Energy Convers. Manage. 183, 84-96 (2019).

${ }^{4}$ J. Benajes, R. Novella, J. M. Pastor, A. Hernández-López, M. Hasegawa, N. Tsuji, M. Emi, I. Uehara, J. Martorell, and M. Alonso, "Optimization of the combustion system of a medium duty direct injection diesel engine by combining CFD modeling with experimental validation," Energy Convers. Manage. 110, 212-229 (2016).

${ }^{\mathbf{5}}$ A. K. Agarwal, S. Gadekar, and A. P. Singh, "In-cylinder air-flow characteristics of different intake port geometries using tomographic PIV," Phys. Fluids 29, 095104 (2017).

${ }^{6}$ A. J. Torregrosa, A. Broatch, R. Novella, and L. F. Mónico, "Suitability analysis of advanced diesel combustion concepts for emissions and noise control," Energy 36, 825-838 (2011).

${ }^{7}$ J. Benajes, A. García, V. Domenech, and R. Durrett, "An investigation of partially premixed compression ignition combustion using gasoline and spark assistance," Appl. Therm. Eng. 52, 468-477 (2013).

${ }^{8}$ A. J. Torregrosa, A. Broatch, R. Novella, J. Gomez-Soriano, and L. F. Mónico, "Impact of gasoline and diesel blends on combustion noise and pollutant emissions in premixed charge compression ignition engines," Energy 137, 58-68 (2017).

${ }^{9}$ A. Broatch, R. Novella, J. García-Tíscar, and J. Gomez-Soriano, "On the shift of acoustic characteristics of compression-ignited engines when operating with gasoline partially premixed combustion," Appl. Therm. Eng. 146, 223-231 (2019). 
${ }^{10}$ A. J. Torregrosa, A. Broatch, A. Gil, and J. Gomez-Soriano, "Numerical approach for assessing combustion noise in compression-ignitied diesel engines," Appl. Acoust. 135, 91-100 (2018).

${ }^{11}$ W. C. Strahle, "Combustion noise," Prog. Energy Combust. Sci. 4, 157-176 (1978).

${ }^{12}$ A. Schwarz and J. Janicka, Combustion Noise (Springer-Verlag, 2009).

${ }^{13}$ M. Schmitt, C. E. Frouzakis, Y. M. Wright, A. G. Tomboulides, and K. Boulouchos, "Investigation of cycle-to-cycle variations in an engine-like geometry," Phys. Fluids 26, 125104 (2014).

${ }^{14}$ F. Zentgraf, E. Baum, B. Böhm, A. Dreizler, and B. Peterson, "On the turbulent flow in piston engines: Coupling of statistical theory quantities and instantaneous turbulence," Phys. Fluids 28, 045108 (2016).

${ }^{15} \mathrm{~L}$. Stanković and J. F. Böhme, "Time-frequency analysis of multiple resonances in combustion engine signals," Signal Process. 79, 15-28 (1999).

${ }^{16} \mathrm{~J}$. Chang, M. Kim, and K. Min, "Detection of misfire and knock in spark ignition engines by wavelet transform of engine block vibration signals," Meas. Sci. Technol. 13, 1108-1114 (2002).

${ }^{17}$ A. J. Torregrosa, A. Broatch, X. Margot, and V. Marant, "Combustion chamber resonances in direct injection automotive diesel engines: A numerical approach," Int. J. Engine Res. 5, 83-91 (2003).

${ }^{18}$ J. M. Desantes, A. J. Torregrosa, and A. Broatch, "Wavelet transform applied to combustion noise analysis in high-speed DI diesel engines," SAE Technical Paper 2001-01-1545, 2001.

${ }^{19}$ A. J. Shahlari, C. Hocking, E. Kurtz, and J. Ghandhi, "Comparison of compression ignition engine noise metrics in low-temperature combustion regimes," SAE Int. J. Engines 6, 541-552 (2013).

${ }^{20} \mathrm{D}$. Anderton, "Relation between combustion system and engine noise," SAE Technical Paper 790270, 1979.

${ }^{21}$ M. F. Russell and R. Haworth, "Combustion noise from high speed direct injection diesel engines," in SAE Surface Vehicle Noise and Vibration Conference, 1985.

${ }^{22}$ F. Payri, A. Broatch, X. Margot, and L. Monelletta, "Sound quality assessment of diesel combustion noise using in-cylinder pressure components," Meas. Sci. Technol. 20, 015107 (2009).

${ }^{23} \mathrm{~F}$. Bi, L. Li, J. Zhang, and T. Ma, "Source identification of gasoline engine noise based on continuous wavelet transform and EEMD-RobustICA," Appl. Acoust. 100, 34-42 (2015).

${ }^{24} \mathrm{X}$. Zhao, Y. Cheng, and S. Ji, "Combustion parameters identification and correction in diesel engine via vibration acceleration signal," Appl. Acoust. 116, 205-215 (2017).

${ }^{25}$ J. Mao, Z.-y. Hao, G.-x. Jing, X. Zheng, and C. Liu, "Sound quality improvement for a four-cylinder diesel engine by the block structure optimization," Appl. Acoust. 74, 150-159 (2013).

${ }^{26}$ F. Duvigneau, T. Luft, J. Hots, J. L. Verhey, H. Rottengruber, and U. Gabbert, "Thermo-acoustic performance of full engine encapsulations-A numerical, experimental and psychoacoustic study," Appl. Acoust. 102, 79-87 (2016).

${ }^{27}$ E. O. Rolland, F. De Domenico, and S. Hochgreb, "Direct and indirect noise generated by entropic and compositional inhomogeneities," J. Eng. Gas Turbines Power 140, 082604 (2018).

${ }^{28}$ D. G. Crighton, A. P. Dowling, J. E. F. Williams, M. Heckl, and F. G. Leppington, "Thermoacoustic sources and instabilities," in Modern Methods in Analytical Acoustics: Lecture Notes (Springer London, London, 1992), pp. 378-405.

${ }^{29}$ A. P. Dowling, "Acoustics of unstable flows," Theor. Appl. Mech. 1996, 171-186 (1997).

${ }^{30}$ W. Strahle, "A review of combustion generated noise," in Aeroacoustics Conference (AIAA, New York, 1975), p. 1023.

${ }^{31}$ F. D. Domenico, E. O. Rolland, and S. Hochgreb, "Detection of direct and indirect noise generated by synthetic hot spots in a duct," J. Sound Vib. 394, 220-236 (2017).

${ }^{32}$ G. Persico, P. Gaetani, and A. Spinelli, "Assessment of synthetic entropy waves for indirect combustion noise experiments in gas turbines," Exp. Therm. Fluid Sci. 88, 376-388 (2017).

${ }^{33}$ S. Busch, K. Zha, A. Warey, F. Pesce, and R. Peterson, "On the reduction of combustion noise by a close-coupled pilot injection in a small-bore direct-injection diesel engine," J. Eng. Gas Turbines Power 138, 102804 (2016).
${ }^{34}$ A. E. W. Austen and T. Priede, "Origins of diesel engine noise," SAE Technical Paper 590127, 1958.

${ }^{35}$ R. Hickling, D. A. Feldmaier, and S. H. Sung, "Knock-induced cavity resonances in open chamber diesel engines," J. Acoust. Soc. Am. 65, 1474-1479 (1979).

${ }^{36}$ A. Kruse, A. Ruziewicz, A. Nemś, and M. Tajmar, "Numerical analysis of competing methods for acoustic field adjustment in a looped-tube thermoacoustic engine with a single stage," Energy Convers. Manage. 181, 26-35 (2019).

${ }^{37}$ T. Priede, "Relation between form of cylinder-pressure diagram and noise in diesel engines," Proc. Inst. Mech. Eng.: Automob. Div. 14, 63-97 (1960).

${ }^{38}$ D. Ibarra, R. Ramírez-Mendoza, and E. López, "Noise emission from alternative fuel vehicles: Study case," Appl. Acoust. 118, 58-65 (2017).

${ }^{39}$ M. Kowada, I. Azumagakito, T. Nagai, N. Iwai, and R. Hiraoka, "Study of knocking damage indexing based on optical measurement," in SAE 2015 World Congress and Exhibition, 2015.

${ }^{40} \mathrm{C}$. S. Draper, "Pressure waves accompanying detonation in the internal combustion engine," J. Aeronaut. Sci. 5, 219-226 (1938).

${ }^{41}$ T. Priede and E. C. Grover, "Paper 2: Noise of industrial diesel engines," Proc. Inst. Mech. Eng., Conf. Proc. 181, 73-89 (1966).

${ }^{42}$ A. Broatch, X. Margot, A. Gil, and C. Donayre, "Computational study of the sensitivity to ignition characteristics of the resonance in DI diesel engine combustion chambers," Eng. Comput. 24, 77-96 (2007).

${ }^{43}$ L. J. Eriksson, "Higher order mode effects in circular ducts and expansion chambers," J. Acoust. Soc. Am. 68, 545-550 (1980).

${ }^{44}$ A. Broatch, R. Novella, J. Gomez-Soriano, P. Pal, and S. Som, "Numerical methodology for optimization of compression-ignited engines considering combustion noise control," SAE Int. J. Engines 11, 625 (2018).

${ }^{45}$ CONVERGE 2.2 Theory Manual, CONVERGENT SCIENCE, Inc., 2015.

${ }^{46} \mathrm{~S}$. B. Pope, "Ten questions concerning the large-eddy simulation of turbulent flows," New J. Phys. 6, 35 (2004).

${ }^{47} \mathrm{~J}$. Smagorinsky, "General circulation experiments with the primitive equations," Mon. Weather Rev. 91, 99-164 (1963).

${ }^{48}$ E. Pomraning and C. J. Rutland, "Dynamic one-equation nonviscosity largeeddy simulation model," AIAA J. 40, 689-701 (2002).

${ }^{49} \mathrm{O}$. Redlich and J. N. S. Kwong, "On the thermodynamics of solutions. V. An equation of state. Fugacities of gaseous solutions," Chem. Rev. 44, 233-244 (1949). ${ }^{50} \mathrm{R}$. I. Issa, "Solution of the implicitly discretised fluid flow equations by operatorsplitting," J. Comput. Phys. 62, 40-65 (1986).

${ }^{51}$ P. K. Senecal, E. Pomraning, K. J. Richards, T. E. Briggs, C. Y. Choi, R. M. McDavid, and M. A. Patterson, "Multi-dimensional modeling of direct-injection diesel spray liquid length and flame lift-off length using CFD and parallel detailed chemistry," SAE Technical Paper 2003-01-1043, 2003.

${ }^{52}$ A. Babajimopoulos, D. N. Assanis, D. L. Flowers, S. M. Aceves, and R. P. Hessel, "A fully coupled computational fluid dynamics and multi-zone model with detailed chemical kinetics for the simulation of premixed charge compression ignition engines," Int. J. Engine Res. 6, 497-512 (2005).

${ }^{53}$ P. Pal, D. Probst, Y. Pei, Y. Zhang, M. Traver, D. Cleary, and S. Som, "Numerical investigation of a gasoline-like fuel in a heavy-duty compression ignition engine using global sensitivity analysis," SAE Int. J. Fuels Lubr. 10, 56-68 (2017).

${ }^{54}$ A. A. Moiz, M. M. Ameen, S.-Y. Lee, and S. Som, "Study of soot production for double injections of $\mathrm{n}$-dodecane in $\mathrm{CI}$ engine-like conditions," Combust. Flame 173, 123-131 (2016).

${ }^{55}$ J. Brakora and R. D. Reitz, "A comprehensive combustion model for biodieselfueled engine simulations," SAE Technical Paper 2013-01-1099, 2013.

${ }^{56}$ J. K. Dukowicz, “A particle-fluid numerical model for liquid sprays," J. Comput. Phys. 35, 229-253 (1980).

${ }^{57}$ R. D. Reitz and J. C. Beale, "Modeling spray atomization with the KelvinHelmholtz/Rayleigh-Taylor hybrid model," Atomization Sprays 9, 623-650 (1999).

${ }^{58}$ P. J. O’Rourke, "Collective drop effects on vaporizing liquid sprays," Ph.D. thesis, Los Alamos National Laboratory, NM, USA, 1981.

${ }^{59}$ A. A. Amsden, P. J. O'rourke, and T. D. Butler, "KIVA-II: A computer program for chemically reactive flows with sprays," Technical Report No. LA-11560-MS, Los Alamos National Laboratory, NM, USA, 1989. 
${ }^{60}$ A. B. Liu, D. Mather, and R. D. Reitz, "Modeling the effects of drop drag and breakup on fuel sprays," in International Congress and Exposition, 1993.

${ }^{61}$ S. Molina, A. García, J. M. Pastor, E. Belarte, and I. Balloul, "Operating range extension of RCCI combustion concept from low to full load in a heavy-duty engine," Appl. Energy 143, 211-227 (2015).

${ }^{62}$ C. Habchi, F. A. Lafossas, P. Béard, and D. Broseta, "Formulation of a onecomponent fuel lumping model to assess the effects of fuel thermodynamic properties on internal combustion engine mixture preparation and combustion," in 2004 SAE Fuels and Lubricants Meeting and Exhibition, 2004.

${ }^{63}$ A. Torregrosa, P. Olmeda, B. Degraeuwe, and M. Reyes, "A concise wall temperature model for DI diesel engines," Appl. Therm. Eng. 26, 1320-1327 (2006).

${ }^{64}$ C. Angelberger, T. Poinsot, and B. Delhay, "Improving near-wall combustion and wall heat transfer modeling in SI engine computations," SAE Technical Paper 2003-01-0542, 1997.

${ }^{65} \mathrm{~F}$. Ihlenburg, "The medium-frequency range in computational acoustics: Practical and numerical aspects," J. Comput. Acoust. 11, 175-193 (2003).

${ }^{66}$ F. Payri, P. Olmeda, J. Martín, and A. García, "A complete 0D thermodynamic predictive model for direct injection diesel engines," Appl. Energy 88, 4632-4641 (2011).

${ }^{67}$ A. J. Torregrosa, A. Broatch, J. García-Tíscar, and J. Gomez-Soriano, "Modal decomposition of the unsteady flow field in compression-ignited combustion chambers," Combust. Flame 188, 469-482 (2018).

${ }^{68}$ C. Lipson and N. J. Sheth, Statistical Design and Analysis of Engineering Experiments (McGraw-Hill, New York, 1973).

${ }^{69}$ D. Probst, S. Wijeyakulasuriya, E. Pomraning, J. Kodavasal, R. Scarcelli, and S. Som, "Predicting cycle-to-cycle variation with concurrent cycles in a gasoline direct injected engine with large eddy simulations," in ASME 2018 Internal Combustion Engine Division Fall Technical Conference (ASME, 2018), p. V002T06A022.

${ }^{70}$ A. Broatch, J. Javier Lopez, J. García-Tíscar, and J. Gomez-Soriano, "Experimental analysis of cyclical dispersion in compression-ignited versus spark-ignited engines and its significance for combustion noise numerical modeling," ASME. J. Eng. Gas Turbines Power 140, 102808 (2018).

${ }^{71}$ A. J. Torregrosa, A. Broatch, J. Martín, and L. Monelletta, "Combustion noise level assessment in direct injection diesel engines by means of in-cylinder pressure components," Meas. Sci. Technol. 18, 2131-2142 (2007).

${ }^{72}$ W. C. Strahle, "Combustion randomness and diesel engine noise: Theory and initial experiments," Combust. Flame 28, 279-290 (1977).

${ }^{73}$ Y. C. Liang, H. P. Lee, S. P. Lim, W. Z. Lin, K. H. Lee, and C. G. Wu, "Proper orthogonal decomposition and its applications-Part I: Theory," J. Sound Vib. 252, 527-544 (2002)

${ }^{74}$ S. Bagheri, "Koopman-mode decomposition of the cylinder wake," J. Fluid Mech. 726, 596-623 (2013).

${ }^{75}$ V. Caux-Brisebois, A. M. Steinberg, C. M. Arndt, and W. Meier, "Thermoacoustic velocity coupling in a swirl stabilized gas turbine model combustor," Combust. Flame 161, 3166-3180 (2014).
${ }^{76}$ H. Chen, D. L. S. Hung, M. Xu, H. Zhuang, and J. Yang, "Proper orthogonal decomposition analysis of fuel spray structure variation in a spark-ignition directinjection optical engine," Exp. Fluids 55, 1703 (2014).

${ }^{77}$ K. Bizon, G. Continillo, S. Lombardi, P. Sementa, and B. M. Vaglieco, "Independent component analysis of cycle resolved combustion images from a spark ignition optical engine," Combust. Flame 163, 258-269 (2016).

${ }^{78}$ S. J. Danby and T. Echekki, "Proper orthogonal decomposition analysis of autoignition simulation data of nonhomogeneous hydrogen-air mixtures," Combust. Flame 144, 126-138 (2006).

${ }^{79}$ J. E. Dec, "A conceptual model of DI diesel combustion based on laser-sheet imaging," in International Congress and Exposition, 1997.

${ }^{80}$ A. Krisman, E. R. Hawkes, M. Talei, A. Bhagatwala, and J. H. Chen, "A direct numerical simulation of cool-flame affected autoignition in diesel engine-relevant conditions," Proc. Combust. Inst. 36, 3567-3575 (2017).

${ }^{81}$ H. Yamashita, M. Shimada, and T. Takeno, "A numerical study on flame stability at the transition point of jet diffusion flames," Symp. (Int.) Combust. 26, 27-34 (1996).

${ }^{82}$ T. Schuller, O. Sauvage, Z. Dimitrijevic, and G. Rymer, "Acoustic analysis of unsteady diesel engine combustion chamber pressure evolution," in 11th AIAA/CEAS Aeroacoustics Conference (AIAA, New York, 2005), p. 2910.

${ }^{83} \mathrm{~J}$. B. Heywood, Internal Combustion Engine Fundamentals (McGraw-Hill, Inc., 1998).

${ }^{84}$ A. J. Torregrosa, A. Broatch, X. Margot, and J. Gomez-Soriano, "Understanding the unsteady pressure field inside combustion chambers of compression ignition engines using a CFD approach," Int. J. Engine Res. (published online).

${ }^{85}$ G. Tissot, L. Cordier, N. Benard, and B. R. Noack, "Model reduction using dynamic mode decomposition," C. R. Mec. 342, 410-416 (2014), part of special issue: Flow separation control.

${ }^{86}$ D. M. Markovich, S. S. Abdurakipov, L. M. Chikishev, V. M. Dulin, and K. Hanjalić, "Comparative analysis of low- and high-swirl confined flames and jets by proper orthogonal and dynamic mode decompositions," Phys. Fluids 26, 065109 (2014).

${ }^{87}$ C. Chen, P. Pal, M. Ameen, D. Feng, and H. Wei, "Large-eddy simulation study on cycle-to-cycle variation of knocking combustion in a spark-ignition engine," Appl. Energy 261, 114447 (2020).

${ }^{88}$ P. Pal, Y. Wu, T. Lu, S. Som, Y. C. See, and A. Le Moine, "Multi-dimensional CFD simulations of knocking combustion in a CFR engine," in ASME 2017 Internal Combustion Engine Division Fall Technical Conference (ASME, 2017), p. V002T06A017.

${ }^{89}$ Y. Pei, P. Pal, Y. Zhang, M. Traver, D. Cleary, C. Futterer, M. Brenner, D. Probst, and S. Som, "CFD-guided combustion system optimization of a gasoline range fuel in a heavy-duty compression ignition engine using automatic piston geometry generation and a supercomputer," SAE Int. J. Adv. Curr. Prac. Mobil. 1, 166 (2019).

${ }^{90}$ P. Pal, C. P. Kolodziej, S. Choi, S. Som, A. Broatch, J. Gomez-Soriano, Y. Wu, T. Lu, and Y. C. See, "A virtual CFR engine model for knocking combustion analysis,” SAE Int. J. Engines 11, 1069 (2018). 